\title{
New Hybrid Optimization for Design of Active Twist Rotors
}

\author{
Devesh Kumar ${ }^{1}$ and Carlos E. S. Cesnik ${ }^{2}$ \\ Department of Aerospace Engineering, The University of Michigan, Ann Arbor, MI 48109
}

\begin{abstract}
This paper presents the development of a mixed-variable optimization framework for the aeroelastic analysis and design of active twist rotors. Proper tailoring of the blade properties can lead to the maximization of the active twist and the control authority for vibration reduction under operating conditions. Thus, using mathematical optimization, the crosssectional layout is designed using continuous and discrete design variables for an active composite rotor blade to maximize the dynamic active twist while satisfying a series of constraints on blade cross section parameters, stiffness and strength. The optimization framework developed includes IXGEN as the cross section and mesh generator, UM/VABS for active cross-sectional analysis, and RCAS for aeroelastic analysis of the active twist rotor blade. The optimization problem is solved using a surrogate-based approach in combination with the Efficient Global Optimization (EGO) algorithm. In this paper, the results with mixed design variables are obtained with three different techniques and are compared with the results obtained using continuous design variables.
\end{abstract}

\section{Introduction}

High vibratory loads observed during forward flight conditions have been one of the primary concerns that have limited the use of helicopters in spite of their superior landing and take-off capabilities. A brief description of all the approaches and the current state of art for vibration reduction in helicopters is described in $[1,2]$. Among the various active control methodologies that have shown potential, the integral twist actuation is one of the promising techniques for vibration reduction without the use of hydraulic power and moving parts in the rotating system. By individually controlling the twist of each blade, the local aerodynamics can be altered to obtain favorable vibration and noise reduction and possible improvement in the performance of the rotor blade. The twist actuation can be obtained by embedding active fiber composites (AFC) or macro fiber composites (MFC) $[3,4]$ in the blade along its span to twist it or to induce warping [5]. But regardless of the technique, there is the need to optimize the material distribution along the blade in order to maximize the twist actuation. The fact that the actuators are also part of the primary blade structure (e.g., changing active ply orientation changes actuation authority and, concomitantly, alters the blade stiffness properties) makes it much more difficult to reach that optimum design. Different attempts have been made to design active twist rotors. The most recent reviews of the different developments associated with the active twist rotor concepts are provided in [2, 6, 7]. In this paper, only the studies relevant to the design and optimization of active twist rotors are discussed.

\section{Active Twist Rotors}

The blade designs of the active twist rotor used in the NASA/Army/MIT Active Twist Rotor (ATR) Program [8] and in the DARPA/Boeing/MIT Program [4] were accomplished through the exploration of several design candidates based on existing passive blades. Among the various candidates, the one with the largest static twist actuation was selected as the final design. No multidisciplinary optimization was used for those designs. The first attempt to introduce mathematical optimization for designing active twist rotor came from Cesnik and co-workers [9-11]. Their optimization framework focused on designing the cross-sectional layouts along the span that maximize the static twist actuation while satisfying the constraints on the chordwise location of cross-sectional center of gravity (CG) and shear center (SC), blade mass per unit length, torsional frequency, and maximum strain throughout the laminates. The design variables used in the analysis were composite ply thickness and angle, chordwise location of the spar web, and ballast mass and its chordwise location. The framework included UM/VABS [12] for active cross-sectional analysis, DYMORE [13] for the geometrically exact beam analysis, a cross-sectional parametric

\footnotetext{
${ }^{1}$ Visiting Scholar (deveshk@umich.edu), AIAA Member.

${ }^{2}$ Professor (cesnik@umich.edu), AIAA Fellow.
} 
mesh generator and MATLAB's gradient based optimizer "fmincon." Among the results, it was shown that the ATR blade [3] could be redesigned to exhibit at least a 30\% higher actuation authority when compared to the original design. Furthermore, [11] demonstrated that a high authority advanced ATR concept could be achieved for an Apache-inspired rotor using the same optimization framework. More recently, Thornburgh et al. [14] performed parametric studies on model-scale blades in order to determine the variables critical for static active twist response using an updated version of the optimization framework of [9-11]. The effects of cross-sectional constraints like mass per unit length, chordwise location of SC and CG, natural frequencies of the blade, and the material stresses on twist rate were also investigated. They further looked at the design of an active cross section for a full-scale rotor and compared the cross-sectional differences between model-scale and full-scale blade designs that are necessary to achieve the maximum twist response during operation. In the Friendcopter program [15], the blade cross section elastic and piezo-induced effects were determined based on 3D ANSYS FEM modeling of a blade section. In that study, the objective was to maximize the twist per unit span of a uniform beam section under given constraints on airfoil shape, chordwise location of CG and SC, torsional frequency and beam stiffness. The design variables used were chordwise location, length and thickness of piezoelectric layer; ballast mass and four geometric parameters that define the front $\mathrm{C}$ spar. A similar framework was used with the response surface technique for optimization in [16, 17]. Approximations of the original functions for constraints and objective function were obtained using low-order polynomials.

Sekula and Wilbur [18-20] conducted a series of parametric design studies with structural and aerodynamic parameters to understand their effect on twist actuation in dynamic conditions. In the parametric study with structural variables [19], the effects on blade active twist, required rotor power, blade loads, and vibratory hub loads were characterized due to the variation in blade torsional, flap-wise and lead-lag stiffness, sectional mass and torsional inertia, and chordwise location of CG and elastic axis. Analyses were conducted using CAMARAD II, and in those studies, the effect of the embedded actuators was represented by torsional moments at the blade root and at the blade tip so to produce equal but opposing loads. In a similar study, the effects of aerodynamic parameters [18, 20] like linear blade twist, blade tip sweep, droop, and taper on active twist performance were determined. Based on the analysis, an advanced active twist rotor (AATR) candidate design with a -10-deg linear twist, a tip region with 30-deg sweep, 10-deg droop, and 2.5:1 taper ratio was proposed. Although the dynamic analysis of the rotor blade was included, the external active twisting moment applied was assumed to be independent of variation in blade structural and aerodynamic properties. Also, the final proposed design was based on trend observations made during the parametric studies and did not use any mathematical optimization technique.

To achieve maximum vibration and/or noise reduction and performance enhancement, the active blades should provide the highest twist authority over a range of rotor frequencies of interest (and not necessarily for the nonrotating, static condition). For a four-bladed rotor, actuation frequencies of 3/rev, 4/rev, and 5/rev are the most effective for vibration reduction. Therefore, the optimization must aim to maximize the twist authority under a range of pre-determined frequencies for the rotor dynamic operating conditions. The sizing of the blade (along with the embedded actuators) needs to be done dynamically, resulting in an optimization problem with the amplitude of dynamic twist at a range of frequencies as its objective function. This is more suitable for optimum active twist rotor blade design.

In a previous work [21], preliminary optimization with dynamic twist as the objective function was performed with a limited number of (six) design variables and it was demonstrated that the dynamic twist obtained from twist actuation is the true measure of control authority for vibration reduction. During the optimization process, the optimizer tries to increase the amplitude of dynamic twist by dynamically tuning the blade`s first torsion frequency and by increasing the chordwise coverage of active material to increase the active twisting moment. Some of the key results from the earlier study are:

1) The design corresponding to maximum static twist is different from the design corresponding to maximum dynamic twist.

2) The optimization studies for maximizing dynamic twist can be performed in hover conditions for the ease of analysis. In the parametric study performed, it was observed that the dynamic twist obtained in hover condition is very close to that obtained in forward flight conditions, for a fixed input voltage.

3) The optimum design obtained at one particular actuation frequency may not be optimum at a different actuation frequency. Hence, while designing an active twist rotor for vibration reduction, it is desirable to increase the amplitude of tip twist at a range of actuation frequencies. 


\section{Optimization for Composite Structures}

Optimization approaches suitable to deal with larger number and different types of design variables are needed to fully explore the active blade design space. In addition to the design variables used in the previous study [21], the thickness and orientation of different plies used in the cross section also need to be considered as design variables. The plies used in the fabrication of composite rotor blade are made up of discrete layers, each with a prescribed thickness (prepreg composites). Therefore, discrete optimization needs to be performed in order to design a realistic rotor blade. Conventional optimization methods are not suitable for working with mixed (both real and integer) type design variables.

Different optimization techniques have been proposed for determining the minimum number of layers in a composite laminate and the best fiber orientation and thickness for each layer. In review papers [22, 23], the main optimization methods are described and their characteristic features are contrasted for constant stiffness design and variable stiffness design. In [24], composite laminate optimization with discrete variables is discussed and issues associated with the design of composite laminates are highlighted. In [25, 26], a novel laminate parameterization technique based on discrete material optimization is used which is well suited for gradient based design optimization to handle problems where ply angles and ply thicknesses are treated as discrete. Most of these studies focus on the design of a simplified composite laminate.

For optimizing complex composite structures where time consuming finite element analysis is required, surrogate modeling and response surface methods are proposed that efficiently explore the design space and limit the number of FEA runs. Surrogate based optimization technique have been used earlier for the design of composite rotor blade [27, 28]. However in these studies, only continuous design variables were considered. Guido et al. [29] presented a mixed continuous-discrete variable optimization for the design of composite panel using surrogate modeling. Here, first a solution with continuous design variables is determined and the solution with mixed design variable is obtained by branching into sub-problems.

For this paper, mixed-variable optimization is performed in three different ways inside a surrogate based optimization framework; namely: a) Direct Mixed-variable Optimization b) Constrained Mixed-variable Optimization and c) Sequential Constrained Gradient-based Optimization. Results obtained from these three optimization techniques are compared with those obtained using continuous optimization. In this paper, continuous optimization is performed using a combination of non-gradient based optimization (GA) and gradient based optimization, as described in [30]. (GA is used to obtain the starting points for gradient based optimization.)

\section{Architecture for Mixed-variable Optimization Framework}

In the case of optimization with $(m+n)$ mixed design variables, some $(m)$ of the variables are continuous while the $(n)$ remaining ones can take discrete values only. A typical vector of $(m+n)$ design variables is shown below:

$$
\mathrm{X}_{\mathrm{DV}}=\left[\mathrm{x}_{\mathrm{c}, 1} \mathrm{x}_{\mathrm{c}, 2} \ldots \ldots \mathrm{x}_{\mathrm{c}, \mathrm{m}} \mathrm{x}_{\mathrm{d}, 1} \mathrm{x}_{\mathrm{d}, 2} \ldots \ldots \mathrm{x}_{\mathrm{d}, \mathrm{n}}\right]
$$

where $x_{c, i}(1 \leq i \leq m)$ are " $m$ " continuous design variables and $x_{d, j}(1 \leq j \leq n)$ are " $n$ " discrete design variables. In the optimization problem considered here, the ply thicknesses and ply angles are treated as discrete design variables while the ballast masses, the chordwise location of vertical spar web, and the chordwise location where the active/spar plies end are treated as continuous design variables. The ply thickness used in this paper is the multiple of the nominal prepreg ply thickness and it is referred to as "normalized ply thickness" in rest of the paper. The basic mixed-variable optimization problem in this paper is solved using the genetic algorithm in MATLAB 2012's Global Optimization Toolbox. It is based on special creation, crossover, and mutation functions which enforce the variables to be integers, as described in [31]. In this paper, the genetic optimization process is combined with the gradient based optimization to obtain an optimum design with continuous design variables and optimum designs with mixed design variables in an efficient manner.

The architecture of the framework used to obtain solution for a mixed-variable optimization problem is shown in Figure 1. It is a modified version of the framework described in [21] which efficiently accounts for:

a) Discrete design variables; and 
b) Increased number of design variables in the optimization problem.

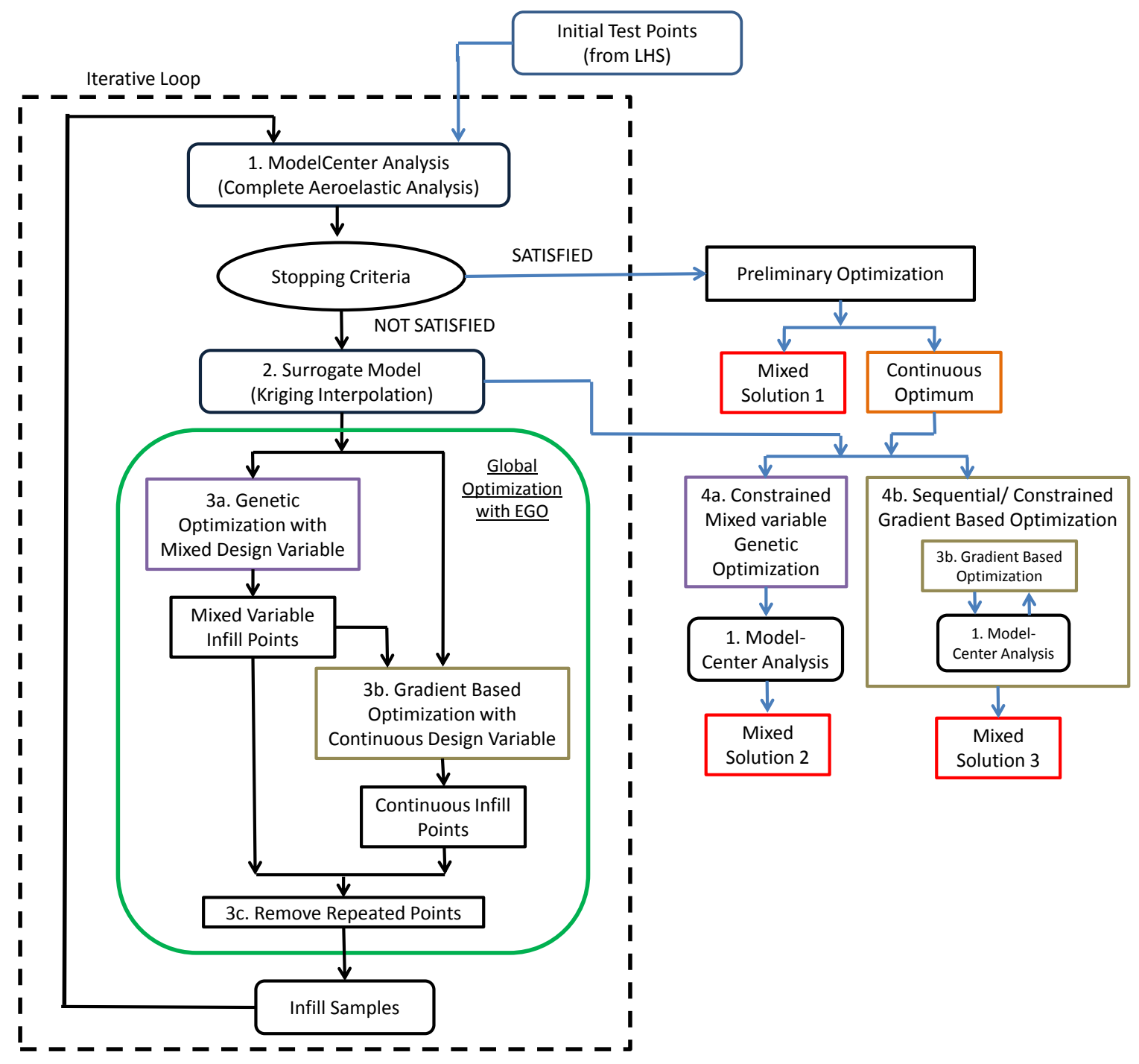

Figure 1: Augmented Optimization Framework for Continuous/Discrete Design Variables

All the steps involved in the mixed-variable optimization framework are described below.

Aeroelastic (ModelCenter) Analysis: In this part, the complete aeroelastic analysis of the active twist rotor is performed. The analysis process described in Figure 2 is a modified version of the work presented in [32, 33], but now accounting for the presence of active materials embedded in the blades. It consists of three main components, namely: IXGEN, UM/VABS and RCAS.

IXGEN [32] (Intelligent Cross section Generator) is a rotor blade modeling environment that allow the user to quickly and easily define a rotor blade as a sequence of cross sections stacked in the spanwise direction along a userdefined stacking axis. IXGEN has two modes of operation - a GUI-driven mode for the designer to set up the blade, and a batch mode for use in an automated design framework, where an optimizer or other type of programmatic design driver modifies the defining parameters and regenerates the blade. Based on the cross-sectional design parameters specified by the user or the optimizer, IXGEN generates the finite element mesh for UM/VABS. 


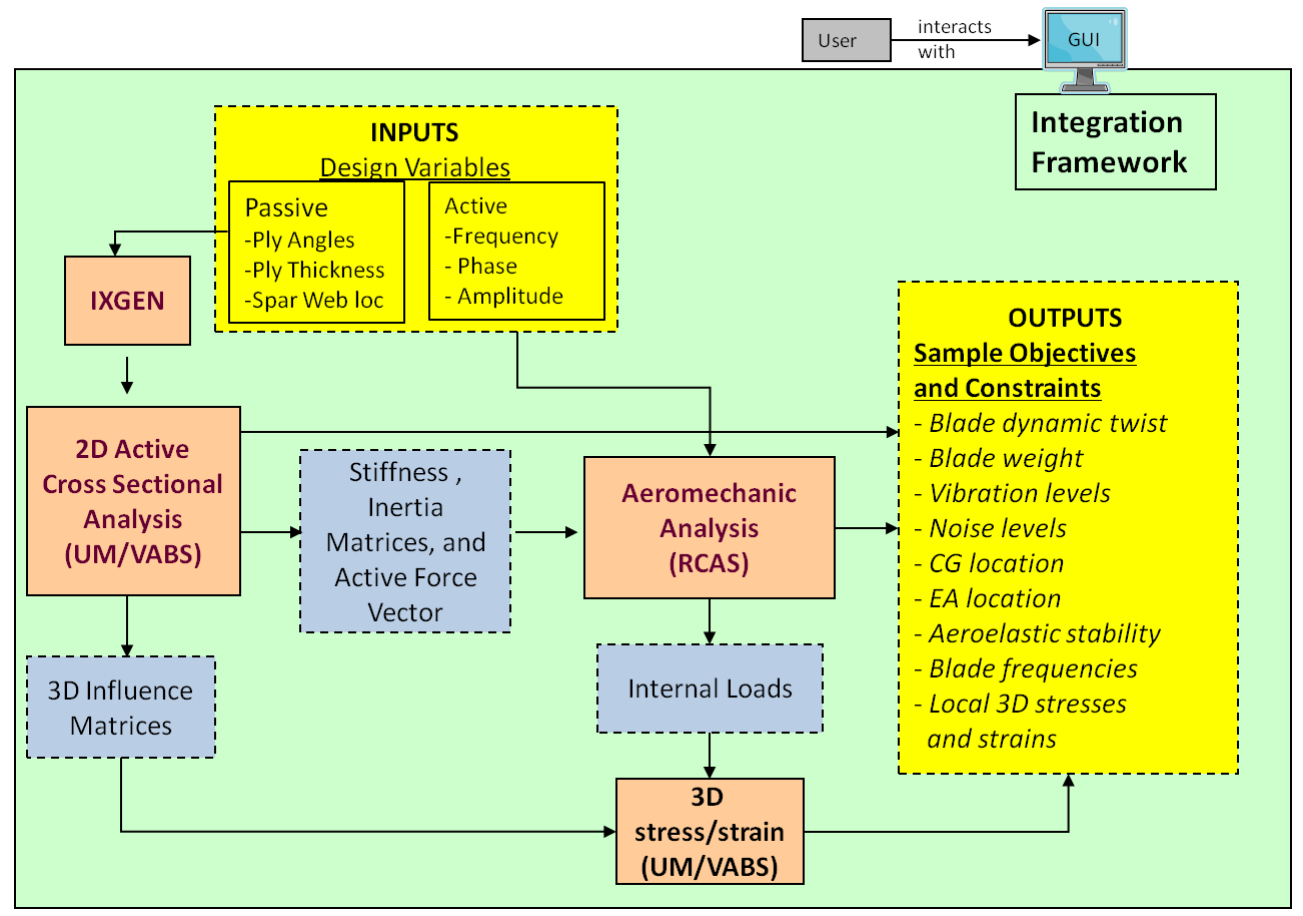

Figure 2: Aeroelastic Analysis Environment for Active Twist Rotors (inside ModelCenter)

In UM/VABS, coupled equations of electrothermo-elasticity in the cross section are solved through an asymptotic approximation [12]. The numerical solution is obtained by finite element discretization of the cross section and there are no restrictions in the cross section geometry or distribution of material properties. UM/VABS provides cross-sectional stiffness, inertia and actuation forces/moments to be used in blade (beam) analysis. It also calculates cross-sectional center of gravity, shear center, and (static) active twist rate.

RCAS (Rotorcraft Comprehensive Analysis System) [34] is a comprehensive multi-disciplinary computer software system for predicting the performance, control, aeroelastic stability, loads and vibration, and aerodynamic characteristics of rotorcraft. The system comprises of an input data processor for setting up analyses, structural and aerodynamic models, and utilities for model assembly and numerical solutions, and an output processor to provide technical data for the full range of rotorcraft technical disciplines. For the RCAS analysis, structural properties of the rotor blades are provided by UM/VABS. The magnitude of the active twisting moment determined using UM/VABS is used as the amplitude of the external twisting moment applied to nodes of the blade in the RCAS beam model. The frequency and phase of the twisting moment are provided by the user or the optimizer. In turn, RCAS evaluates the blade dynamic twist response for the prescribed frequency range, which will be used as the objective function.

Finally, all these solvers are wrapped in ModelCenter [35]. Any parameter used by IXGEN in the geometry parameterization can be used as a design variable for optimization or parametric studies. A linking scheme allows the user to link parameters to design variables such that one design variable drives a number of rotor blade parameters. This significantly reduces the size of the optimization problem and also makes it easy to enforce practical manufacturing constraints. Any response parameter produced by either UM/VABS or RCAS that is exposed by this environment is available to the next level (optimizer) as either a constraint or objective function. In order to reduce the computational time for the aeroelastic analysis, the "Periodic Analysis" is performed instead of using the "Trim Analysis" (discussed in more detail in the following section). All the cases are run in hover condition.

Stopping Criteria: The stopping criteria can either be based on the maximum number of iterations allowed or on the difference between the optimal value of the objective function obtained from successive iterations. In the analysis performed here, the optimization process was stopped after four to six iterations. It was observed during the 
optimization process that the difference between the successive optimal point reduced and the accuracy of the surrogate models improved with each iteration.

Surrogate Modeling: The goal of using surrogate models [36,37] is to replace the true objective function and constraints with smooth functional relationships of acceptable fidelity that can be evaluated quickly. To form the surrogates, the objective function must first be evaluated over an initial set of design points. The surrogate is then generated by interpolating the initial design points. Although function evaluations coming from the expensive aeroelastic simulation are needed to form the approximation, this initial investment of computer time is significantly less than that needed in a global search using non-surrogate based optimization methods. Moreover, experience shows that not all parameter combinations of design variables will result in successful RCAS runs. Therefore, few missing points in the construction of the surrogates due to failed RCAS runs do not impact their accuracy or ability to provide solution. The increased robustness of the process has a direct impact on the ability to completely explore the entire design space.

The MATLAB Latin hypercube function "Ihsdesign" was used to generate the space-filling design of experiments used in this study. The points in the Latin hypercube represent design points at which complete aeroelastic helicopter simulations are to be conducted. Once an initial set of fitting points has been produced, kriging interpolation [38] is used to create the surrogate for the objective function and constraints. Kriging interpolation is well suited to approximating nonlinear functions, and does not require a priori assumptions on the form of the function that is to be approximated. The kriging surrogates were created with an available MATLAB toolbox [39].

Global Optimization with EGO Algorithm: Once the surrogate models are created using kriging, a potential method for finding the optimum is to perform optimization using the surrogates directly, i.e., the "one-shot" approach. However, if the surrogates are not accurate everywhere in the design space, the optimization may lead to local optima. Therefore, it is desirable to account for the uncertainty in the surrogate models since promising designs could lie in regions where the surrogates are inaccurate. The Efficient Global Optimization (EGO) algorithm [40] is an alternative to the "one-shot" approach which accounts for uncertainty in the surrogate and is more efficient. The effectiveness of the EGO algorithm for passive design of helicopter rotors for vibration reduction was demonstrated in [41]. In EGO, a small number of initial design points are used to fit a kriging approximation. Based on the stochastic nature of kriging, an expected improvement function (EIF) is created in order to facilitate the selection of additional sample points (infill samples) where expensive computer simulations are to be conducted. These sample points are chosen where there is a high probability of producing a superior design over the current best design and/or where the predictions of the surrogate are unreliable due to a high amount of uncertainty. Therefore, the EGO algorithm is able to adapt to potential errors in the approximate objective function by sampling at points at which there is much uncertainty in the surrogate's predictions. The kriging model is revised after the additional sample data is added to the initial data set, and the process of choosing additional sample points is repeated until a user defined criterion is satisfied. For the optimization studies performed in this paper, the EGO algorithm accounts for uncertainty in the prediction of objective function only. For the constraints, the value predicted by the surrogate models is used directly in the optimization. In summary, the advantages of such a method over the "one-shot" approach are: (1) a global search is conducted by sampling in regions with high uncertainty in the surrogate, and (2) fewer expensive function evaluations are required since a smaller initial sample set is used and additional sample points are selected in a more "intelligent" manner, as opposed to starting with a larger initial data set.

The global optimization with EGO algorithm was performed in multiple steps to account for: the mixed design variables and to reduce the computational time. In the first step, genetic optimization is performed with mixed design variables where some of the design variables are continuous while the remaining ones are discrete. It was observed that the genetic algorithm works faster when some of the variables are treated as discrete instead of the case when all the design variables are continuous. Hence, genetic optimization was used to obtain optimum results with mixed design variables only. The results obtained from this analysis are referred to as "Mixed-variable Infill Points." It should be noted that multiple points (a set of best 5-10 points) are selected at the end of each optimization and not just the one optimum point. These multiple points represent different local minima in the design space and form a part of the Infill Samples for the next round of iteration. These "Mixed-variable Infill Points" are also used as the starting points for the gradient based optimization performed on the surrogate models. The gradient based optimizer provides a set of continuous optimum points. The gradient based optimization is performed using the "fmincon" function in MATLAB. The set of points obtained at the end of the continuous optimization are referred as "Continuous Infill Points." 
The set of best points obtained from genetic optimization and gradient based optimization are used as Infill Samples. Before transferring these points to the next stage, repeated points are removed from the analysis by checking the absolute distance between the design points.

Iterative Loop: The complete aeroelastic analysis is performed again at the Infill Sample points using the ModelCenter Framework. The results obtained from new points are used to update the surrogate model for all the constraints and the objective function. The process of global optimization with genetic algorithm and gradient based optimization is performed again. The iterative loop is repeated for four to six iterations.

Preliminary results: At the end of the iterative loop, the set of points which satisfy all the constraints are sorted in the order of increasing objective function. The best point obtained is referred as "Continuous Optimum" and it represents the best design point with continuous design variables. Next, the points where the normalized ply thicknesses (or ply angles) have discrete values are sorted out of the group. The point with the best objective function in this group is referred to as "Mixed Solution 1." This point is the most optimum solution obtained at the end of the iterative loop where the discrete design variables have integer values only.

The mixed-variable solution can also be obtained in two other different ways using the "Continuous Optimum" point obtained earlier. In the first method, the genetic optimization for mixed design variable is used, while the second method involves the usage of a gradient-based optimizer. These two methods are described in detail here.

a) Constrained Mixed-variable Genetic Optimization

This optimization is similar to what was performed in "Optimization with EGO algorithm", except that the bounds for discrete design variables are modified such that a discrete solution is determined near the "Continuous Optimum" point. For example, if the "Continuous Optimum" point gives a value of 1.36 for the normalized ply thickness, then a lower bound of "1" and an upper bound of "2" is used for this ply thickness in the genetic optimization. The bounds for a continuous design variable are kept unchanged during this process. A sample case is shown in Table 1 where the optimization is performed with 12 design variables. Of these 12 design variables, four are continuous while the remaining eight can take discrete values only. The initial upper and lower bounds for these design variables (as used in "Optimization with EGO algorithm") are shown by the rows corresponding to $\mathrm{X}_{\text {upper }}$ and $\mathrm{X}_{\text {lower }}$, respectively. The "Continuous Optimum" solution obtained at the end of Preliminary Optimization is shown by $\mathrm{X}_{\mathrm{opt}}$. Based on the optimum result obtained, the upper and lower bounds on the design variables are modified to $X^{\prime}$ upper and $\mathrm{X}^{\prime}$ lower, respectively. Note that in this step, only the bounds for discrete design variables are modified while the bounds on continuous design variables remain unchanged. The mixed-variable solution obtained at the end of this optimization process is referred as "Mixed Solution 2."

Table 1: Modified Bounds for Constrained Mixed-variable Genetic Optimization

\begin{tabular}{|c|c|c|c|c|c|c|c|c|c|c|c|c|}
\hline & $\mathrm{x}_{\mathrm{c} 1}$ & $\mathrm{x}_{\mathrm{c} 2}$ & $\mathrm{x}_{\mathrm{c} 3}$ & $\mathrm{x}_{\mathrm{c} 4}$ & $\mathrm{x}_{\mathrm{d} 1}$ & $\mathrm{x}_{\mathrm{d} 2}$ & $\mathrm{x}_{\mathrm{d} 3}$ & $\mathrm{x}_{\mathrm{d} 4}$ & $\mathrm{x}_{\mathrm{d} 5}$ & $\mathrm{x}_{\mathrm{d} 6}$ & $\mathrm{x}_{\mathrm{d} 7}$ & $\mathrm{x}_{\mathrm{d} 8}$ \\
\hline \multicolumn{13}{|c|}{ Bounds for Original Mixed-variable Genetic Optimization } \\
\hline$X_{\text {upper }}$ & 0.85 & 0.85 & 0.5 & 0.5 & 5 & 5 & 5 & 5 & 5 & 5 & 5 & 5 \\
\hline $\mathrm{X}_{\text {lower }}$ & 0.2 & 0.2 & 0 & 0 & 0 & 0 & 0 & 0 & 0 & 0 & 0 & 0 \\
\hline \multicolumn{13}{|c|}{ Solution Obtained from Continuous Gradient-Based Optimization } \\
\hline $\mathrm{X}_{\mathrm{opt}}$ & 0.85 & 0.84 & 0.29 & 0.012 & 0.10 & 4.93 & 1.16 & 0.10 & 1.31 & 0.10 & 0.54 & 0.64 \\
\hline \multicolumn{13}{|c|}{ Modified Bounds for Constrained Mixed-variable Optimization } \\
\hline$X_{\text {upper }}^{\prime}$ & 0.85 & 0.85 & 0.5 & 0.5 & 1 & 5 & 2 & 1 & 2 & 1 & 1 & 1 \\
\hline $\mathrm{X}^{\prime}$ lower & 0.2 & 0.2 & 0 & 0 & 0 & 4 & 1 & 0 & 1 & 0 & 0 & 0 \\
\hline
\end{tabular}

b) Sequential Constrained Gradient-based optimization

Another approach for obtaining a mixed-variable solution using the "Continuous Optimum" design is the classical sequential optimization approach which can be performed using a gradient based optimizer. In this approach, if any of the discrete design variables in $\mathrm{X}_{\mathrm{opt}}$ has a value close to an integer, then the value for that particular design variable is fixed to that integer value and it is not considered a design variable anymore. For example, in the results shown in Table 1, the value corresponding to $\mathrm{x}_{\mathrm{d} 2}$ is 4.93 in $\mathrm{X}_{\mathrm{opt}}$. Since 
this value is very close " 5 ", the value for this design variable is fixed to " 5 " and it is not considered a design variable. Similarly, the value of design variables $\mathrm{x}_{\mathrm{d} 1}, \mathrm{x}_{\mathrm{d} 4}$ and $\mathrm{x}_{\mathrm{d} 6}$ is fixed to " 0 ". The modified vector of design variables and their upper and lower bounds for the next gradient-based optimization study are shown in Table 2. In the next step, the value of one more discrete design variable is fixed to an integer value and the process repeated till all the discrete design variable have been assigned an integer value. In this particular case, the gradient based optimization had to be performed four more times in order to get the final mixed-variable solution. The solution obtained at the end of this method is referred as "Mixed Solution 3."

Table 2: Modified Set of Design Variables for Sequential Gradient-Based Optimization

\begin{tabular}{|ccccccccc|}
\hline & $\mathrm{X}_{\mathrm{c} 1}$ & $\mathrm{X}_{\mathrm{c} 2}$ & $\mathrm{X}_{\mathrm{c} 3}$ & $\mathrm{X}_{\mathrm{c} 4}$ & $\mathrm{X}_{\mathrm{d} 3}$ & $\mathrm{X}_{\mathrm{d} 5}$ & $\mathrm{X}_{\mathrm{d} 7}$ & $\mathrm{x}_{\mathrm{d} 8}$ \\
\hline $\mathrm{X}_{\text {upper }}$ & 0.85 & 0.85 & 0.5 & 0.5 & 5 & 5 & 5 & 5 \\
$\mathrm{X}_{\text {lower }}$ & 0.2 & 0.2 & 0 & 0 & 0 & 0 & 0 & 0 \\
\hline
\end{tabular}

This optimization technique has the advantage that it provides a mixed-variable solution using a gradientbased optimizer. However, the optimization needs to be performed multiples times depending upon the number of discrete design variables in the problem. Every time, the time to convergence decreases as the size of the problem decreases and the starting condition are very close to the optimum. Hence, the Sequential Gradient Based Optimization approach may be time-consuming.

\section{Optimization Problem Definition}

\section{Baseline Rotor Blade}

The baseline rotor blade used for the optimization studies in this paper is the NASA/Army/MIT Active Twist Rotor (ATR), as described in [21]. The ATR blade [8, 42] was originally designed to study the effects of twist actuation on vibration and noise reduction and performance improvement in helicopter rotors. The 9-ft-diameter four-bladed rotor was tested at NASA LaRC's Transonic Dynamics Tunnel and was the first-of-a-kind system to demonstrate vibration reduction using embedded active fiber composites (AFC) in open and closed loop forward flight conditions [43]. This particular rotor blade was chosen for this study due to its known properties and available experimental and computational results [3]. Figure 3 shows the planform view of the blade and its corresponding dimensions. The airfoil for this blade is the NACA 0012 and it is uniform along the blade radius. The reference cross-sectional layup is shown in Figure 4, while Table 3 lists the ply angles for all the plies used in the cross section of the rotor blade. Among the plies used, E-Glass is bidirectional while S-glass and AFC plies are unidirectional. The specific material properties can be found in Table 4 .

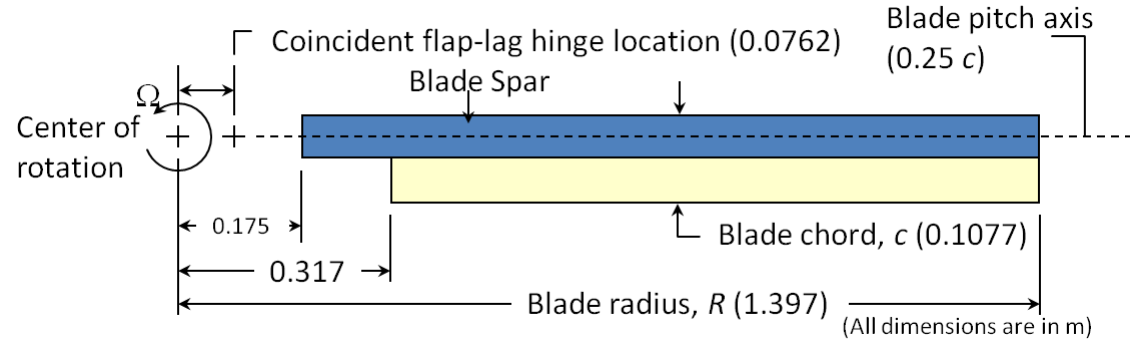

Figure 3: Planform View of the ATR Rotor Blade (Dimensions in Meters)

The characteristic properties of the baseline ATR blade and its structural frequencies at 100\% RPM are listed in Table 3. Blade structural frequencies in vacuum were obtained using RCAS. For trim analysis, the trim targets used in the analysis are: $C_{T}=0.0066$, no cyclic moments $\left(M_{x}=0\right.$ and $\left.M_{y}=0\right)$, and the blade pitch settings are used as the trim variables (wind-tunnel trim). 


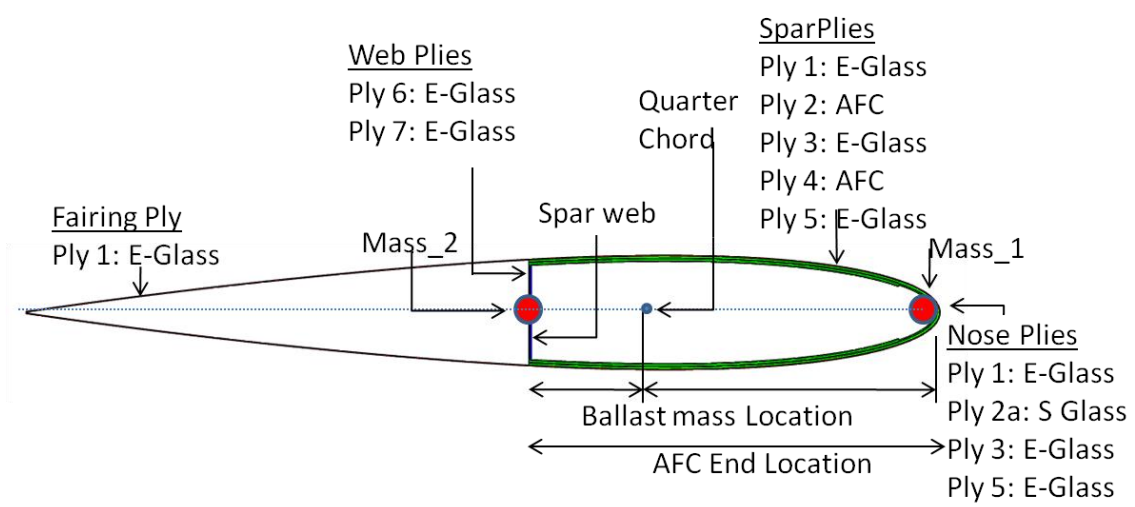

Figure 4: Cross-Sectional Shape of the Rotor Blade (NACA 0012 Airfoil)

Table 3: Ply Angles for the Different Plies in the Baseline ATR Cross Section

\begin{tabular}{|c|c|c|c|}
\hline Ply \# & Angle (deg) & Ply \# & Angle (deg) \\
\hline Ply 1 & $0 / 90$ & Ply 6 & $0 / 90$ \\
Ply 2 & 45 & Ply 7 & $0 / 90$ \\
\cline { 3 - 4 } Ply 2a & 0 & \multicolumn{2}{|}{} \\
Ply 3 & \pm 45 & & \\
Ply 4 & -45 & & \\
Ply 5 & $0 / 90$ & \multicolumn{2}{|l}{} \\
\cline { 1 - 3 } & &
\end{tabular}

Table 4: Material Properties

\begin{tabular}{|c|c|c|c|}
\hline & E-Glass & S-Glass & AFC \\
\hline Thickness $(\mu \mathrm{m})$ & 114.3 & 230 & 200 \\
Density $\left(\mathrm{kg} / \mathrm{m}^{3}\right)$ & 1720 & 1860 & 4060 \\
$\mathrm{E}_{11}(\mathrm{GPa})$ & 20.7 & 43.4 & 30.2 \\
$\mathrm{E}_{22}(\mathrm{GPa})$ & 20.7 & 12 & 14.9 \\
$\mathrm{E}_{33}(\mathrm{GPa})$ & 20.7 & 12 & 14.9 \\
$\mathrm{G}_{12}(\mathrm{GPa})$ & 4.1 & 3.6 & 5.13 \\
$\mathrm{G}_{13}(\mathrm{GPa})$ & 4.1 & 3.6 & 5.13 \\
$\mathrm{G}_{23}(\mathrm{GPa})$ & 4.1 & 3.6 & 5.13 \\
$v_{12}$ & 0.13 & 0.28 & 0.454 \\
$v_{13}$ & 0.13 & 0.28 & 0.454 \\
$v_{23}$ & 0.3 & 0.3 & 0.3 \\
\hline
\end{tabular}

Table 5: Characteristics of the Baseline ATR

\begin{tabular}{|c|c|}
\hline Rotor Type & Fully Articulated \\
Number of blades & 4 \\
Blade radius (R) & $1.397 \mathrm{~m}$ \\
Blade Chord (c) & $0.1077 \mathrm{~m}$ \\
Airfoil Section & NACA 0012 \\
Blade Pretwist & $-10 \mathrm{deg}$ \\
Hinge Offset & $0.0762 \mathrm{~m}$ \\
Rotor Speed & $687.5 \mathrm{RPM}$ \\
$\mathrm{C}_{\mathrm{T}}$ & 0.0066 \\
Air density & $2.42 \mathrm{~kg} / \mathrm{m}^{3}$ \\
\hline
\end{tabular}

\begin{tabular}{|c|c|}
\hline Mode Shape & Frequency $(/ \mathrm{rev})$ \\
\hline $1^{\text {st }}$ Chordwise bending & 0.29 \\
$1^{\text {st }}$ Flapwise bending & 1.04 \\
$2^{\text {nd }}$ Flapwise bending & 2.78 \\
$3^{\text {rd }}$ Flapwise bending & 5.34 \\
$2^{\text {nd }}$ Chordwise bending & 5.76 \\
$1^{\text {st }}$ Torsion & 6.51 \\
\hline
\end{tabular}

9

American Institute of Aeronautics and Astronautics 


\section{Design Variables and Constraints}

In the first study, the normalized ply thicknesses of different plies used in the cross section are considered as design variables, along with the variables described in [21]. In order to make the rotor blade design more realistic, the location of first ballast mass is fixed near the leading edge at $\mathrm{x}=0.02 \mathrm{c}$ while the second ballast mass is located just in front of the vertical spar web. (This is done to ensure that the ballast mass is added in the region where passive plies can be used to support it and thus prevent the ballast mass from flying out during the operation). Due to these changes, there were small changes in the dynamic properties of the baseline case. The set of design variables and their upper and lower bounds are given in Table 6. In order to prevent the mesh generator from crashing, the lower bound on normalized ply thickness is fixed at 0.1 instead of zero. A value of 0.1 for normalized ply thickness in an optimum design implies that that particular ply is not required in the cross section and should be removed in the next optimization. The constraints used in the optimization are listed in Table 7.

Table 6: Design Variables and their Bounds

\begin{tabular}{|c|c|c|c|c|c|}
\hline & Design variables & Baseline & Lower & Upper & Ply Type \\
\hline 1 & Main Spar Loc (c) & 0.443 & 0.2 & 0.85 & \\
2 & Spar End (c) & 0.443 & 0.2 & 0.85 & \\
3 & Ballast Mass 1 $\left(\mathrm{m}_{1}\right)(\mathrm{kg} / \mathrm{m})$ & 0.23 & 0 & 0.5 & \\
4 & Ballast Mass 2 $\left(\mathrm{m}_{2}\right)(\mathrm{kg} / \mathrm{m})$ & 0.22 & 0 & 0.5 & \\
\hline 5 & Normalized Thickness of Ply 1 & 1 & 0.1 & 5 & E-Glass \\
6 & Normalized Thickness of Ply 2a & 1 & 0.1 & 5 & S-Glass \\
7 & Normalized Thickness of Ply 2 & 1 & 0.1 & 5 & AFC \\
8 & Normalized Thickness of Ply 3 & 1 & 0.1 & 5 & E-Glass \\
9 & Normalized Thickness of Ply 4 & 1 & 0.1 & 5 & AFC \\
10 & Normalized Thickness of Ply 5 & 1 & 0.1 & 5 & E-Glass \\
\hline 11 & Normalized Thickness of Ply 6 & 1 & 0.1 & 5 & E-Glass \\
12 & Normalized Thickness of Ply 7 & 1 & 0.1 & 5 & E-Glass \\
\hline
\end{tabular}

Table 7: Constraints for Optimization Problem

\begin{tabular}{|c|c|c|}
\hline Constraints & Min & Max \\
\hline $\mathrm{SC}(\% \mathrm{c})$ & 17 & 25 \\
$\mathrm{CG}(\% \mathrm{c})$ & 20 & 28 \\
$\mathrm{M}_{11}(\mathrm{~kg} / \mathrm{m})$ & 0.65 & 0.72 \\
$1^{\text {st }}$ Tor Freq $(/ \mathrm{rev})$ & 3.0 & 7 \\
\hline
\end{tabular}

Objective functions which are considered for optimization studies are listed below:

1) Maximize the static twist per unit length (Max $\left.\theta_{\text {stat }}\right)$

2) Maximize the amplitude of twist for $3 / \mathrm{rev}$ actuation $\left(\operatorname{Max} \theta_{3 / \mathrm{rev}}\right)$

3) Maximize the amplitude of twist for $4 / \mathrm{rev}$ actuation $\left(\operatorname{Max} \theta_{4 / \mathrm{rev}}\right)$

4) Maximize the amplitude of twist for $5 / \mathrm{rev}$ actuation (Max $\theta_{5 / \text { rev }}$ )

5) Maximize the amplitude of twist at 3, 4 and 5/rev actuation simultaneously (Max $\theta_{345 / \text { rev }}$ ). The objective function for this case is defined by:

$$
\theta_{345 / \text { rev }}=\frac{1}{3}\left[\frac{\theta_{3 / \text { rev }}}{\theta_{3 / \text { rev }, \text { max }}}+\frac{\theta_{4 / \text { rev }}}{\theta_{4 / \text { rev }, \text { max }}}+\frac{\theta_{5 / \text { rev }}}{\theta_{5 / \text { rev }, \text { max }}}\right]
$$

where, $\theta_{3 / \text { rev, } \max }$ is the maximum amplitude of tip twist obtained from optimization at $3 /$ rev actuation frequency, $\theta_{4 / \text { rev, } \max }$ is the maximum amplitude of tip twist obtained from optimization at $4 / \mathrm{rev}$ actuation frequency, and $\theta_{5 / \text { rev, } \max }$ is the maximum amplitude of tip twist obtained from optimization at $5 /$ rev actuation frequency. 


\section{Periodic Analysis}

Ideally, the trim analysis is required in aeroelastic simulations to determine accurate blade deformations. However, the trim analysis is very time consuming and each run in RCAS takes 15-20 min for a complete aeroelastic analysis. As a result, the possibility of using Periodic Analysis for aeroelastic simulations inside RCAS was considered. In this case, the pitch settings are kept constant and a periodic solution is obtained. The rest of the analysis variables are kept the same. Thus, the blade experiences similar aerodynamic stiffness (aerodynamic forces per unit blade twist) as in the trim cases but the magnitude of aerodynamic loads is small since the initial pitch settings used are very close to zero. The computation time (on an Intel Core 2 Quad CPU@2.40 GHz) required for a "Periodic Analysis" ( $\sim 1 \mathrm{~min})$ is an order of magnitude less than the computational time required for the "Trim Analysis" ( $\sim 15 \mathrm{~min})$. The "Periodic Analysis" can only be used to approximate the amplitude of blade deformation due to actuation of on-blade active devices. The amplitude and mean value of tip twist for active twist actuation at 3 , 4 and 5/rev actuation frequencies for the baseline ATR blade at $\mu=0.0$ are shown in Figure 5. As show in Figure 5, the amplitude of tip twist predicted by "Trim Analysis" and "Periodic Analysis" are very close to each other, however there is a significant difference in the mean value of tip twist predicted by the two analyses. Since the amplitude of dynamic twist is used as the objective function in this paper, the "Periodic Analysis" is performed for all the aeroelastic simulations inside the optimization framework.
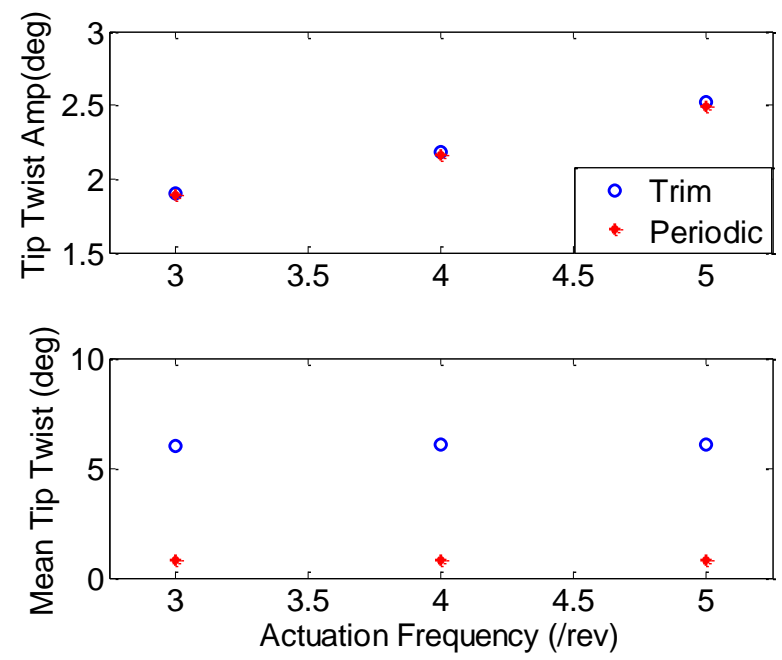

Figure 5: Variation of Mean Value and Amplitude of Tip Twist for twist actuation at $\boldsymbol{\mu}=\mathbf{0 . 0}$

\section{Optimization Results}

Final results obtained for the objective functions at the end of optimization are shown in Table 8 . The results show the optimum value of objective function when all the design variables are treated as continuous and when the normalized ply thicknesses are treated as discrete (obtained from all the three mixed-variable optimization techniques described in Figure 1).

Table 8: Final Result obtained from Optimization Studies

\begin{tabular}{|c|ccccc|}
\hline & $\begin{array}{c}\operatorname{Max} \theta_{\text {stat }} \\
(\mathrm{deg} / \mathrm{m})\end{array}$ & $\begin{array}{c}\operatorname{Max} \theta_{3 / \text { rev }} \\
(\mathrm{deg})\end{array}$ & $\begin{array}{c}\operatorname{Max} \theta_{4 / \text { rev }} \\
(\mathrm{deg})\end{array}$ & $\begin{array}{c}\text { Max } \theta_{5 / \text { rev }} \\
(\mathrm{deg})\end{array}$ & Max $\theta_{345 / \text { rev }}$ \\
\hline Continuous Optimum & 2.59 & 5.69 & 6.56 & 7.97 & 0.89 \\
Mixed Solution 1 & 2.56 & 4.24 & 5.88 & 7.79 & 0.87 \\
Mixed Solution 2 & 2.55 & 4.19 & 6.01 & 7.93 & 0.89 \\
Mixed Solution 3 & 2.55 & 4.18 & 5.85 & 7.98 & 0.89 \\
Baseline & 1.34 & 1.85 & 2.06 & 2.34 & 0.31 \\
\hline
\end{tabular}


The results show that the value of objective function corresponding to optimization with continuous design variables is always better than those obtained for the cases with mixed design variables. In general, the results obtained from the three mixed-variable optimization techniques are close to each other. The most interesting aspect of these results is the difference between the value of the objective function when all the variables are treated as continuous and when the variables are of mixed type. The percentage difference between the value of objective function for the continuous variable case and the average value of objective function for the mixed-variable cases is shown in Table 9. The percentage difference is less than $1.5 \%$ for Max $\theta_{\text {stat }}, \operatorname{Max} \theta_{5 / \text { rev }}$ and Max $\theta_{345 / \text { rev }}$ cases, while it is highest for the Max $\theta_{3 / \text { rev }}$ case.

\section{Table 9: Percentage Difference between the Objective Function for Continuous Variable Optimization and Mixed-variable Optimization}

\begin{tabular}{|c|ccccc|}
\hline & $\operatorname{Max} \theta_{\text {stat }}$ & $\operatorname{Max} \theta_{3 / \text { rev }}$ & $\operatorname{Max} \theta_{4 / \text { rev }}$ & $\operatorname{Max} \theta_{5 / \text { rev }}$ & $\operatorname{Max} \theta_{345 / \text { rev }}$ \\
\hline Difference (\%) & 1.42 & 26.13 & 9.86 & 0.88 & 1.20 \\
\hline
\end{tabular}

\section{Optimization with Continuous Design Variables}

The value of design variables and constraints for the optimization cases with continuous design variables and for the baseline case is shown in Table 10. As observed earlier, the most critical parameter for maximizing the dynamic twist is the first torsion frequency of the blade. The optimizer tries to bring the first torsion frequency of the blade closer to the actuation frequency. The chordwise location of CG for all the cases is closer to the aft constraint limit on CG location. This can be attributed to the increase in the value of design variable "Spar End" which is at its upper limit. By increasing the chordwise coverage of the active/spar plies, higher active twisting moment can be obtained, which would also result in an increase in the dynamic twist. The chordwise location of the vertical spar web is very close to the "Spar End" value for all the optimized cases. This results in a box-type spar for all the optimized cases. The increase in the chordwise coverage of plies in the cross section leads to an increase in the torsional stiffness. For all the optimized cases (except the Max $\theta_{3 / \text { rev }}$ case), the torsional stiffness of the optimum blade is higher than that for the baseline case, even though the first torsion frequency is lower. The placement of the first torsion frequency for the optimized cases is controlled by manipulating the values of two ballast masses. The amount of ballast mass used in the cross section is highest for the Max $\theta_{3 / \text { rev }}$ case and it is least for the Max $\theta_{\text {stat }}$ case. Thus, the two ballast masses play an important role in varying the first torsional frequency of the blade.

Among the ply thickness design variables, the normalized ply thickness of all passive plies (Ply 1, Ply 3 and Ply 5) in the spar region have been reduced to their minimum allowable value. This was expected since they do not contribute to the active twist. However, the nose ply (Ply 2a) is very important for obtaining higher active twisting moment and hence all the optimized cases show an increase in the normalized thickness of nose ply. The plies in the vertical spar web (Ply 6 and Ply 7) need to have sufficient stiffness in order to control the chordwise location of the shear center. Hence, even though these are passive plies, the normalized ply thickness for the spar web plies is not close to zero.

An increase in the normalized thickness of active plies is also accompanied by a corresponding increase in the torsional stiffness for the cross section. Hence, different optimized cases have different values for the normalized thickness of active plies (Ply 2 and Ply 4), depending upon the actuation frequency. The thickness of active plies is highest for the Max $\theta_{\text {stat }}$ case while it is the least for the Max $\theta_{3 / \text { rev }}$ case. The results obtained for normalized ply thickness also demonstrate that, for the fixed amount of active material available, it is preferable to increase the chordwise coverage of active material as compared to increasing the thickness of active plies in order to get a higher dynamic twist amplitude. Another important trend observed is the direct correlation between torsional stiffness (GJ) of the cross section and the active twisting moment generated by the embedded active plies. For all the optimized cases, the normalized thickness of the inner active ply (Ply 4) is higher than that of the outer active ply (Ply 2).

The performance of the optimized cases at different actuation frequencies is shown in Table 11. Each column represents one of the optimized cases as listed in Table 10. The tip-twist values listed in Table 11 are nondimensionalized by the maximum value obtained for that objective function during the optimization study (except for $\theta_{345 / \text { rev }}$ ). The results show that the value of static twist is very close to the maximum value that can be obtained for Max $\theta_{4 / \text { rev }}$, Max $\theta_{5 / \text { rev }}$ and Max $\theta_{345 / \text { rev }}$ cases. This table also highlights that the optimum solution obtained at one 
actuation frequency may not be optimum at a different actuation frequency, and hence the optimization needs to be performed at a range of actuation frequencies. The solution obtained by maximizing $\theta_{345 / \mathrm{rev}}$ shows high values of dynamic twist for all the actuation frequencies considered.

Table 10: Constraints and Design Variables for Optimization with Continuous Design Variables

\begin{tabular}{|ccccccc|}
\hline & Baseline & Max $\theta_{\text {stat }}$ & Max $\theta_{3 / \text { rev }}$ & Max $\theta_{4 \text { rev }}$ & Max $\theta_{5 / \text { rev }}$ & Max $\theta_{345 / \text { rev }}$ \\
\hline Constraints & & & & & & \\
$1^{\text {st }}$ Tor Freq (/rev) & 6.53 & 5.9 & 3.71 & 4.86 & 5.6 & 5.09 \\
$\mathrm{M}_{11}(\mathrm{~kg} / \mathrm{m})$ & 0.682 & 0.701 & 0.7 & 0.719 & 0.717 & 0.719 \\
$\mathrm{SC}(\% \mathrm{c})$ & 18.71 & 23.5 & 17.07 & 19.12 & 24.82 & 18.98 \\
CG $(\% \mathrm{c})$ & 21.64 & 27.22 & 26.46 & 27.92 & 27.41 & 27.8 \\
\hline Continuous Variables & & & & & & \\
Spar End (c) & 0.443 & 0.85 & 0.818 & 0.85 & 0.842 & 0.85 \\
Main web (c) & 0.443 & 0.84 & 0.813 & 0.85 & 0.834 & 0.85 \\
$\mathrm{~m}_{1}(\mathrm{~kg} / \mathrm{m})$ & 0.23 & 0.299 & 0.397 & 0.346 & 0.32 & 0.334 \\
$\mathrm{~m}_{2}(\mathrm{~kg} / \mathrm{m})$ & 0.22 & 0.012 & 0.123 & 0.06 & 0.034 & 0.047 \\
\hline Discrete Variables (Normalized Ply Thickness) & & & & \\
Ply 1 & 1 & 0.1 & 0.16 & 0.1 & 0.11 & 0.1 \\
Ply 2a & 1 & 4.93 & 2.40 & 5 & 4.84 & 5 \\
Ply 2 & 1 & 1.16 & 0.41 & 0.84 & 1.03 & 0.98 \\
Ply 3 & 1 & 0.1 & 0.10 & 0.1 & 0.10 & 0.1 \\
Ply 4 & 1 & 1.31 & 0.68 & 1.09 & 1.27 & 1.12 \\
Ply 5 & 1 & 0.1 & 0.17 & 0.1 & 0.1 & 0.1 \\
Ply 6 & 1 & 0.59 & 0.26 & 0.43 & 0.54 & 0.59 \\
Ply 7 & 1 & 0.64 & 0.10 & 0.25 & 0.82 & 0.1 \\
\hline Other Parameters & & & & & & \\
S 4 (Nm ${ }^{2}$ ) & 37.7 & 62.4 & 28.8 & 49.2 & 60.1 & 52.3 \\
Act Mom (Nm) & 0.91 & 2.83 & 1.16 & 2.21 & 2.70 & 2.37 \\
$2^{\text {nd }}$ Flap Freq (/rev) & 2.76 & 2.75 & 2.67 & 2.72 & 2.74 & 2.73 \\
$3^{\text {rd }}$ Flap Freq (/rev) & 5.26 & 5.33 & 4.80 & 5.14 & 5.26 & 5.19 \\
\hline
\end{tabular}

Table 11: Performance of Optimized Cases at other Actuation Frequencies

\begin{tabular}{|ccccccc|}
\hline Cases & Baseline & $\operatorname{Max} \theta_{\text {stat }}$ & $\operatorname{Max} \theta_{3 / \text { rev }}$ & $\operatorname{Max} \theta_{4 / \text { rev }}$ & Max $\theta_{5 / \text { rev }}$ & Max $\theta_{345 / \text { rev }}$ \\
\hline $\bar{\theta}_{\text {stat }}$ & 0.52 & 1 & 0.87 & 0.98 & 0.99 & 0.99 \\
$\bar{\theta}_{3 / \text { rev }}$ & 0.33 & 0.68 & 1 & 0.81 & 0.69 & 0.77 \\
$\bar{\theta}_{4 / \text { rev }}$ & 0.31 & 0.73 & 0.55 & 1 & 0.78 & 0.93 \\
$\bar{\theta}_{\text {//rev }}$ & 0.29 & 0.91 & 0.16 & 0.81 & 1 & 0.97 \\
$\theta_{345 / \text { rev }}$ & 0.31 & 0.77 & 0.57 & 0.87 & 0.82 & 0.89 \\
\hline
\end{tabular}

where, $\bar{\theta}_{\text {stat }}=\frac{\theta_{\text {stat }}}{\theta_{\text {stat } \text {, } \max }}, \bar{\theta}_{3 / \mathrm{rev}}=\frac{\theta_{3 / \mathrm{rev}}}{\theta_{3 / \text { rev }, \text { max }}}, \bar{\theta}_{4 / \mathrm{rev}}=\frac{\theta_{4 / \mathrm{rev}}}{\theta_{4 / \mathrm{rev}, \max }}$ and $\bar{\theta}_{5 / \mathrm{rev}}=\frac{\theta_{5 / \mathrm{rev}}}{\theta_{5 / \mathrm{rev}, \max }}$;

and $\theta_{\text {stat, } \max }=2.59, \theta_{3 / \text { rev, } \max }=5.69, \theta_{4 / \text { rev, } \max }=6.56$, and $\theta_{5 / \text { rev, } \text { max }}=7.97$ 


\section{Optimization with Mixed Design Variables}

In this section, the results obtained from the optimization with continuous design variables are compared with those obtained using mixed-variable for each of the objective function described above. As discussed earlier, in the case of mixed design variable optimization, four of the twelve design variables are treated as continuous while the remaining eight are discrete and can take integer values only. In this case also, the lower bound on the normalized ply thickness was fixed at 0.1 instead of zero to prevent the mesh generator from crashing.

\section{Maximizing $\theta_{\text {stat }}$}

The final results obtained from maximizing $\theta_{\text {stat }}$ using the optimization process described in Section 2 are shown in Table 12.

Table 12: Optimization Results for Maximizing $\theta_{\text {stat }}$

\begin{tabular}{|c|c|c|c|c|}
\hline Objective Function & $\begin{array}{c}\text { Continuous } \\
\text { Optimum }\end{array}$ & $\begin{array}{c}\text { Mixed } \\
\text { Solution } 1 \\
\end{array}$ & $\begin{array}{c}\text { Mixed } \\
\text { Solution } 2 \\
\end{array}$ & $\begin{array}{c}\text { Mixed } \\
\text { Solution } 3 \\
\end{array}$ \\
\hline$\theta_{\text {stat }}(\mathrm{deg} / \mathrm{m})$ & 2.59 & 2.56 & 2.57 & 2.57 \\
\hline Constraints & & & & \\
\hline Tor Freq (/rev) & 5.90 & 5.14 & 5.33 & 5.11 \\
\hline $\mathrm{M}_{11}(\mathrm{~kg} / \mathrm{m})$ & 0.701 & 0.712 & 0.720 & 0.719 \\
\hline $\mathrm{SC}(\% \mathrm{c})$ & 23.50 & 24.52 & 23.43 & 23.43 \\
\hline $\mathrm{CG}(\% \mathrm{c})$ & 27.22 & 27.28 & 20.55 & 27.72 \\
\hline \multicolumn{5}{|l|}{ Continuous Variables } \\
\hline Spar End (c) & 0.850 & 0.847 & 0.850 & 0.850 \\
\hline Main web (c) & 0.840 & 0.844 & 0.850 & 0.850 \\
\hline $\mathrm{m}_{1}(\mathrm{~kg} / \mathrm{m})$ & 0.299 & 0.342 & 0.361 & 0.342 \\
\hline $\mathrm{m}_{2}(\mathrm{~kg} / \mathrm{m})$ & 0.012 & 0.052 & 0.035 & 0.054 \\
\hline \multicolumn{5}{|c|}{ Discrete Variables (Normalized Ply Thickness) } \\
\hline Ply 1 & 0.10 & 0.1 & 0.1 & 0.1 \\
\hline Ply 2a & 4.93 & 4 & 5 & 5 \\
\hline Ply 2 & 1.16 & 1 & 1 & 1 \\
\hline Ply 3 & 0.10 & 0.1 & 0.1 & 0.1 \\
\hline Ply 4 & 1.31 & 1 & 1 & 1 \\
\hline Ply 5 & 0.10 & 0.1 & 0.1 & 0.1 \\
\hline Ply 6 & 0.54 & 0.1 & 1 & 0.1 \\
\hline Ply 7 & 0.64 & 1 & 0.1 & 1 \\
\hline
\end{tabular}

For Max $\theta_{\text {stat }}$ case, the difference in the value of objective function between the optimization with continuous design variables and the optimization with mixed design variables is less than $1.5 \%$. Although, the final values of the objective function for the optimized cases are close, there is a noticeable difference between the optimum designs. Also, the difference between the results obtained from the three different techniques used for optimization with mixed design variables is small. The biggest difference between the continuous variable and mixed-variable case lies in the value of first torsion frequency for the optimized cases. In the continuous variable case, the active plies, Ply 2 and Ply 4, have thickness 16\% and 30\% higher than those for the mixed-variable cases, respectively. Due to this, the optimum designs with mixed design variables has less torsional stiffness and the embedded active plies generate less active twisting moment. This also highlights that multiple local minima exist in the design space being considered. The mixed-variable cases also show an increase in the magnitude of leading edge ballast mass and a corresponding increase in the mass per unit length for the cross section.

\section{Maximizing $\theta_{3 / \text { rev }}$}

The results obtained by maximizing $\theta_{3 / \text { rev }}$ using continuous and mixed design variables are shown in Table 13 . For this case, while the three results obtained with mixed design variables are close to each other, there is a $26 \%$ 
difference between the optimum values of objective function as compared to the continuous variable case. The main reason for this is the discretization of normalized thickness for the active plies. In order to reduce the torsional frequency (and torsional stiffness) of the blade, the normalized thickness of active plies in the cross section is well below "one" for the continuous design variable cases. But when the normalized thickness of active plies is rounded to "one" for the mixed-variable case, there is a significant increase in the torsional stiffness of the cross section which could not be completely offset by adding more ballast mass. As a result, all the cases with mixed design variables show a higher torsional frequency and thus lower amplitude for the dynamic twist.

Table 13: Optimization Results for Maximizing $\theta_{3 / \text { rev }}$

\begin{tabular}{|c|c|c|c|c|}
\hline Objective Function & $\begin{array}{c}\text { Continuous } \\
\text { Optimum }\end{array}$ & $\begin{array}{c}\text { Mixed } \\
\text { Solution } 1 \\
\end{array}$ & $\begin{array}{c}\text { Mixed } \\
\text { Solution } 2\end{array}$ & $\begin{array}{c}\text { Mixed } \\
\text { Solution } 3 \\
\end{array}$ \\
\hline$\theta_{3 / \text { rev }}(\operatorname{deg})$ & 5.69 & 4.24 & 4.19 & 4.18 \\
\hline Constraints & & & & \\
\hline $1^{\text {st }}$ Tor Freq $(/ \mathrm{rev})$ & 3.71 & 5.15 & 4.81 & 5.11 \\
\hline $\mathrm{M}_{11}(\mathrm{~kg} / \mathrm{m})$ & 0.700 & 0.694 & 0.683 & 0.718 \\
\hline $\mathrm{SC}(\% \mathrm{c})$ & 17.07 & 19.91 & 17.27 & 23.74 \\
\hline $\mathrm{CG}(\% \mathrm{c})$ & 26.46 & 26.93 & 27.35 & 27.61 \\
\hline \multicolumn{5}{|l|}{ Continuous Variables } \\
\hline Spar End (c ) & 0.818 & 0.845 & 0.828 & 0.816 \\
\hline Main web (c ) & 0.813 & 0.846 & 0.599 & 0.816 \\
\hline $\mathrm{m}_{1}(\mathrm{~kg} / \mathrm{m})$ & 0.397 & 0.326 & 0.309 & 0.343 \\
\hline $\mathrm{m}_{2}(\mathrm{~kg} / \mathrm{m})$ & 0.123 & 0.046 & 0.072 & 0.068 \\
\hline \multicolumn{5}{|c|}{ Discrete Variables (Normalized Ply Thickness) } \\
\hline Ply 1 & 0.16 & 0.1 & 0.1 & 0.1 \\
\hline Ply $2 \mathrm{a}$ & 2.40 & 5 & 2 & 4 \\
\hline Ply 2 & 0.41 & 1 & 1 & 1 \\
\hline Ply 3 & 0.10 & 0.1 & 0.1 & 0.1 \\
\hline Ply 4 & 0.68 & 1 & 1 & 1 \\
\hline Ply 5 & 0.17 & 0.1 & 0.1 & 0.1 \\
\hline Ply 6 & 0.26 & 1 & 0.1 & 0.1 \\
\hline Ply 7 & 0.10 & 0.1 & 1 & 1 \\
\hline
\end{tabular}

Small differences can be observed among the three results obtained with mixed design variables. In the "Mixed Solution 1", five plies are used in the nose region which gives higher active twisting moment. Thus, the "Mixed Solution 1" provides the maximum dynamic twist amplitude inspite of having the highest torsional frequency. In the case of "Mixed Solution 2", the vertical spar web is located near mid chord and the first torsional frequency is closer to the actuation frequency of $3 / \mathrm{rev}$. Thus, the optimizer is trying to increase the amplitude of dynamic twist by reducing the first torsion frequency.

Maximizing $\theta_{4 \text { rev }}$

The optimization results obtained by maximizing $\theta_{4 / \text { rev }}$ with continuous and mixed design variables are shown in Table 14. In this case, the difference between the optimum value of the objective function obtained using continuous design variables and mixed design variables is $9.9 \%$. Here, the normalized thickness of active plies is closer to their discrete value, than they were in the case of "Maximizing $\theta_{3 / \text { rev }}$ " Besides the thickness of active plies and vertical spar web plies, there is very small difference in the optimum design obtained with continuous design variables and mixed design variables. Among the different results with mixed design variables, the "Mixed Solution 2" gives the best result since it has more plies in the nose region which result in a higher active twisting moment. 
Table 14: Optimization Results for Maximizing $\theta_{4 / r e v}$

\begin{tabular}{|c|cccc|}
\hline Objective Function & $\begin{array}{c}\text { Continuous } \\
\text { Optimum }\end{array}$ & $\begin{array}{c}\text { Mixed } \\
\text { Solution 1 }\end{array}$ & $\begin{array}{c}\text { Mixed } \\
\text { Solution 2 }\end{array}$ & $\begin{array}{c}\text { Mixed } \\
\text { Solution 3 }\end{array}$ \\
\hline$\theta_{4 / \text { rev }}(\mathrm{deg})$ & 6.56 & 5.88 & 6.01 & 5.85 \\
\hline \multicolumn{5}{|c|}{ Constraints } \\
\hline $1^{\text {st }}$ Tor Freq $(/ \mathrm{rev})$ & 4.86 & 5.13 & 5.11 & 5.10 \\
$\mathrm{M}_{11}(\mathrm{~kg} / \mathrm{m})$ & 0.719 & 0.714 & 0.719 & 0.719 \\
$\mathrm{SC}(\% \mathrm{c})$ & 19.12 & 24.50 & 23.43 & 23.80 \\
$\mathrm{CG}(\% \mathrm{c})$ & 27.92 & 27.54 & 27.79 & 27.81 \\
\hline \multicolumn{5}{|c|}{ Continuous Variables } \\
\hline Spar End (c) & 0.850 & 0.849 \\
Main web (c) & 0.850 & 0.842 & 0.850 & 0.819 \\
$\mathrm{~m}_{1}(\mathrm{~kg} / \mathrm{m})$ & 0.346 & 0.342 & 0.341 & 0.819 \\
$\mathrm{~m}_{2}(\mathrm{~kg} / \mathrm{m})$ & 0.060 & 0.053 & 0.054 & 0.068 \\
\hline \multicolumn{5}{|c|}{ Discrete Variables (Normalized Ply Thickness) } \\
\hline Ply 1 & 0.10 & 0.10 & 0.10 & 0.10 \\
Ply 2a & 5.00 & 4 & 5 & 4 \\
Ply 2 & 0.84 & 1 & 1 & 1 \\
Ply 3 & 0.10 & 0.10 & 0.10 & 0.10 \\
Ply 4 & 1.09 & 1 & 1 & 1 \\
Ply 5 & 0.10 & 0.10 & 0.10 & 0.10 \\
Ply 6 & 0.43 & 1 & 1 & 0.10 \\
Ply 7 & 0.25 & 0.10 & 0.10 & 1 \\
\hline
\end{tabular}

Maximizing $\theta_{5 / \text { rev }}$

The results obtained for maximizing the amplitude of dynamic twist at 5/rev actuation frequency with continuous and mixed design variables are shown in Table 15. Unlike the results obtained for "Maximizing $\theta_{3 / \text { rev }}$ " and "Maximizing $\theta_{4 / \text { rev }}$ " cases, the difference between the optimum value of the objective function obtained using continuous design variables and mixed design variables is very small. In the optimization with continuous design variable, the normalized thickness of active plies is more than 1 in order to obtain higher active twisting moment. However, in the case of mixed design variables, a higher dynamic twist is obtained by placing the first torsion frequency closer to the actuation frequency. Also, the mixed design variables results show slightly heavier ballast mass in the spar region to increase the torsional inertia for the cross section and to further reduce the torsion frequency as compared to the continuous design variable case.

For this particular optimization study, the optimum design shown in "Mixed Solution 3" is slightly better than that obtained for Continuous Optimum, which contrary to the expected trend. This implies that the result obtained with continuous design variables is not the optimum solution and it should be possible to find a better solution. However, the difference between optimum values predicted by "Continuous Optimum" and "Mixed Solution 3" is very small and is within the error in the prediction of $\theta_{5 / \text { rev }}$ by the surrogate model.

Maximizing $\theta_{345 / r e v}$

Finally, the result obtained for maximizing $\theta_{345 / \text { rev }}$ using continuous and mixed design variables are shown in Table 16. In this case also, the optimum result obtained from optimization with mixed design variables is very close to that obtained using continuous design variables. 
Table 15 Optimization Results for Maximizing $\theta_{5 / \text { rev }}$

\begin{tabular}{|c|cccc|}
\hline Objective Function & $\begin{array}{c}\text { Continuous } \\
\text { Optimum }\end{array}$ & $\begin{array}{c}\text { Mixed } \\
\text { Solution 1 }\end{array}$ & $\begin{array}{c}\text { Mixed } \\
\text { Solution 2 }\end{array}$ & $\begin{array}{c}\text { Mixed } \\
\text { Solution 3 }\end{array}$ \\
\hline$\theta_{5 \text { /rev }}(\mathrm{deg})$ & 7.97 & 7.79 & 7.93 & 7.98 \\
\hline \multicolumn{5}{|c|}{ Constraints } \\
\hline $1^{\text {st }}$ Tor Freq (/rev) & 5.60 & 5.20 & 5.10 & 5.22 \\
$\mathrm{M}_{11}(\mathrm{~kg} / \mathrm{m})$ & 0.717 & 0.704 & 0.720 & 0.698 \\
$\mathrm{SC}(\% \mathrm{c})$ & 24.8 & 23.2 & 23.5 & 23.4 \\
$\mathrm{CG}(\% \mathrm{c})$ & 27.4 & 27.4 & 28.0 & 27.9 \\
\hline \multicolumn{5}{|c|}{ Continuous Variables } \\
\hline Spar End (c) & 0.842 & 0.850 & 0.850 & 0.848 \\
Main web (c ) & 0.834 & 0.833 & 0.850 & 0.841 \\
$\mathrm{~m}_{1}(\mathrm{~kg} / \mathrm{m})$ & 0.320 & 0.331 & 0.342 & 0.326 \\
$\mathrm{~m}_{2}(\mathrm{~kg} / \mathrm{m})$ & 0.034 & 0.050 & 0.055 & 0.050 \\
\hline \multicolumn{5}{|c|}{ Discrete Variables (Normalized Ply Thickness) } \\
\hline Ply 1 & 0.11 & 0.1 & 0.1 & 0.1 \\
Ply 2a & 4.84 & 5 & 5 & 5 \\
Ply 2 & 1.03 & 1 & 1 & 1 \\
Ply 3 & 0.10 & 0.1 & 0.1 & 0.1 \\
Ply 4 & 1.27 & 1 & 1 & 1 \\
Ply 5 & 0.10 & 0.1 & 0.1 & 0.1 \\
Ply 6 & 0.54 & 0.1 & 0.1 & 0.1 \\
Ply 7 & 0.82 & 1 & 1 & 1 \\
\hline
\end{tabular}

Table 16: Optimization Results for Maximizing $\boldsymbol{\theta}_{345 / r e v}$

\begin{tabular}{|c|cccc|}
\hline Objective Function & $\begin{array}{c}\text { Continuous } \\
\text { Optimum }\end{array}$ & $\begin{array}{c}\text { Mixed } \\
\text { Solution 1 }\end{array}$ & $\begin{array}{c}\text { Mixed } \\
\text { Solution 2 }\end{array}$ & $\begin{array}{c}\text { Mixed } \\
\text { Solution 3 }\end{array}$ \\
\hline$\theta_{345 / \text { rev }}$ & 0.89 & 0.87 & 0.88 & 0.89 \\
\hline \multicolumn{5}{|c|}{ Constraints } \\
\hline $1^{\text {st }}$ Tor Freq (/rev) & 5.09 & 5.13 & 5.08 & 5.11 \\
$\mathrm{M}_{11}(\mathrm{~kg} / \mathrm{m})$ & 0.719 & 0.714 & 0.719 & 0.719 \\
$\mathrm{SC}(\% \mathrm{c})$ & 18.98 & 24.50 & 24.51 & 23.43 \\
$\mathrm{CG}(\% \mathrm{c})$ & 27.80 & 27.54 & 27.99 & 27.82 \\
\hline \multicolumn{5}{|c|}{ Continuous Variables } \\
\hline Spar End (c) & 0.850 & 0.849 & 0.848 & 0.850 \\
Main web (c) & 0.850 & 0.842 & 0.848 & 0.850 \\
$\mathrm{~m}_{1}(\mathrm{~kg} / \mathrm{m})$ & 0.334 & 0.342 & 0.346 & 0.341 \\
$\mathrm{~m}_{2}(\mathrm{~kg} / \mathrm{m})$ & 0.047 & 0.053 & 0.056 & 0.054 \\
\hline \multicolumn{5}{|c|}{ Discrete Variables (Normalized Ply Thickness) } \\
\hline Ply 1 & 0.10 & 0.1 & 0.1 & 0.1 \\
Ply 2a & 5.00 & 4 & 4 & 5 \\
Ply 2 & 0.98 & 1 & 1 & 1 \\
Ply 3 & 0.10 & 0.1 & 0.1 & 0.1 \\
Ply 4 & 1.12 & 1 & 1 & 1 \\
Ply 5 & 0.10 & 0.1 & 0.1 & 0.1 \\
Ply 6 & 0.59 & 1 & 0.1 & 0.1 \\
Ply 7 & 0.10 & 0.1 & 1 & 1 \\
\hline
\end{tabular}


In this section, the optimization studies were conducted with twelve design variables, where four of the design variables were continuous while the remaining eight were discrete. Here, the optimum solution was obtained using continuous design variables and mixed design variables in order to compare the two results and obtain a feasible design, which can be readily manufactured. The results showed that in some cases it is possible to get results with mixed design variables very close to those obtained with continuous design variables, depending upon the objective function.

\section{Optimization Study with Ply Thicknesses and Ply Angles}

In order to prevent the mesh generator from crashing, the minimum allowable normalized ply thickness was fixed to " 0.1 " instead of using " 0 " for the optimization studies performed earlier. The optimization results obtained showed that the optimizer tried to reduce the normalized thickness of all passive plies in the spar region (Ply 1, Ply 3 and Ply 5) to 0.1 indicating that these plies do not contribute to the dynamic twist amplitude and hence, these plies should not be included in the cross section. Therefore, in the optimization study presented in this section, Ply 3 and Ply 5 are removed from the analysis. Since Ply 1 is the outermost ply, it cannot be removed from the cross section. Thus, the normalized thickness of Ply 1 is fixed to minimum possible thickness, which is "one", for all the studies presented in this section. Also, in order to reduce the number of design variables, both the plies in the vertical spar web region (Ply 6 and Ply 7) are grouped and they are treated as one equivalent ply (Ply 6) whose thickness is a design variable. The modified cross section which is used as the baseline case is shown in Figure 6 and is referred to as "Baseline 2" in rest of the paper. The final set of design variables used in this study and their upper and lower bounds are listed in Table 17. The constraints used in this study are the same as those listed in Table 7.

The bounds used for ply angle depends on the nature of the prepreg. For the unidirectional plies, the ply angle varies from -90 to +90 degrees, whereas for the bidirectional plies, the ply angle varies from 0 to 90 degrees. Even though the ply angle can be treated as a continuous design variable, it is difficult to accurately manufacture a composite structure where the ply angle has a real value. Hence, in the mixed-variable optimization performed here, the ply angles are treated as discrete design variables for the ease of manufacturing. In some of the earlier work [44], ply angles are discretized in multiples of 5 or 10 degree. The framework presented here is also capable of working with this discretization, however for the analysis presented in this section; the ply angle is allowed to take any integer value within the bounds specified.

Table 17: Design Variables for Optimization with Ply Thicknesses and Ply Angles

\begin{tabular}{|c|c|c|c|c|c|}
\hline & Design variables & Baseline 2 & Lower & Upper & Ply Type \\
\hline 1 & Main Spar Loc (c) & 0.443 & 0.2 & 0.85 & \\
\hline 2 & Spar End (c) & 0.443 & 0.2 & 0.85 & \\
\hline 3 & Ballast Mass $1\left(\mathrm{~m}_{1}\right)(\mathrm{kg} / \mathrm{m})$ & 0.23 & 0 & 0.5 & \\
\hline 4 & Ballast Mass $2\left(\mathrm{~m}_{2}\right)(\mathrm{kg} / \mathrm{m})$ & 0.22 & 0 & 0.5 & \\
\hline \multicolumn{6}{|c|}{$\begin{array}{l}\text { Normalized Ply Thickness } \\
\end{array}$} \\
\hline 5 & Ply 2a Thickness & 1 & 1 & 5 & S-Glass \\
\hline 6 & Ply 2 Thickness & 1 & 1 & 5 & $\mathrm{AFC}$ \\
\hline 7 & Ply 4 Thickness & 1 & 1 & 5 & $\mathrm{AFC}$ \\
\hline 8 & Spar Web Ply 6 Thickness & 1 & 1 & 10 & E-Glass \\
\hline \multicolumn{6}{|c|}{ Ply Angles } \\
\hline 9 & Ply 1 Angle & 0 & 0 & 90 & E-Glass \\
\hline 10 & Ply 2a Angle & 0 & -90 & 90 & S-Glass \\
\hline 11 & Ply 2 Angle & 45 & -90 & 90 & $\mathrm{AFC}$ \\
\hline 12 & Ply 4 Angle & -45 & 0 & 90 & $\mathrm{AFC}$ \\
\hline 13 & Spar Web Ply 6 Angle & 0 & 0 & 90 & E-Glass \\
\hline
\end{tabular}




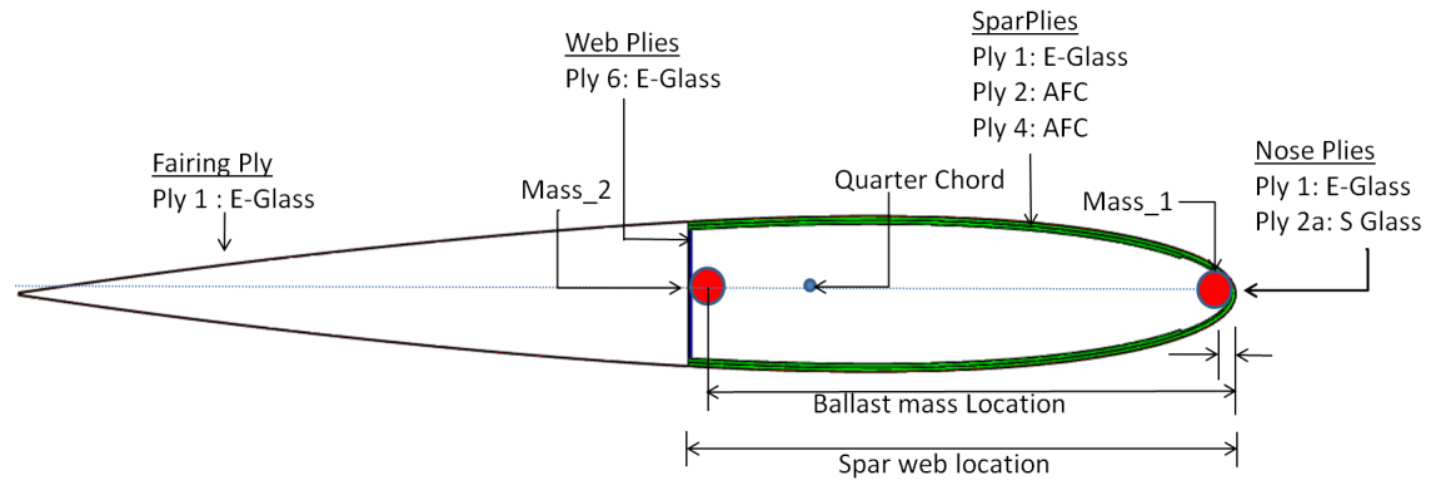

Figure 6: Modified Baseline Case (Baseline 2)

\section{Optimization Results with Continuous Design Variables}

The results obtained, when all the design variables listed in Table 17 are treated as continuous design variables, are shown in Table 18. For some of the objective functions, it was observed that the final value of ply angles do not vary from their baseline values. This is true for the Max $\theta_{\text {stat }}$ and Max $\theta_{4 / \text { rev }}$ cases shown in Table 18.

For the Max $\theta_{\text {stat }}$ case, three of the constraints namely, mass per unit length and chordwise location of CG and SC are close to their upper bound. This occurs, because there is an increase in the thickness of all the plies used in the cross section and the chordwise coverage of active plies is at the maximum allowable value. Here, only the leadingedge ballast mass is used to get the chordwise location of CG within the bounds required. Among the ply thicknesses, the thickness of the nose ply is very close to the maximum allowable value since it results in a higher active twisting moment. There is an increase of $23 \%$ in the normalized thickness of active plies, namely, Ply 2 and Ply 4. Among all the optimized cases, the Max $\theta_{\text {stat }}$ case has the highest cross-sectional stiffness.

In the Max $\theta_{3 / r e v}$ case, the presence of the outermost passive ply does not permit significant reduction in the first torsional frequency, as it was possible in the previous optimization study. Thus, the first torsion frequency and cross-sectional torsional stiffness obtained for the Max $\theta_{3 / \text { rev }}$ case in Table 18 is higher than that obtained for the $\operatorname{Max} \theta_{3 / \text { rev }}$ case in Table 10. As a consequence of this, the value of objective function for the optimized case in Table 18 is significantly lower than that obtained in Table 10. The vertical spar web is located near the quarter chord due to which the chordwise location of shear center is closer to its lower limit. Unlike the Max $\theta_{\text {stat }}$ case, the normalized thickness of the nose ply, Ply 2a, is at its minimum value while the normalized thickness of vertical spar web ply, Ply 6, is at the maximum allowable value. Thus, in the Max $\theta_{3 / \text { rev }}$ case, the optimizer is trying to lower the torsional stiffness as much as possible in order to get the first torsion frequency closer to the actuation frequency. The results for Max $\theta_{3 / \text { rev }}$ case show a very small variation in ply angles. The ply angle for active plies is away from \pm 45 degrees. Although the active twisting moment generated is reduced due to the ply angle changes, the lowering of the torsional frequency results in a higher dynamic twist at the blade tip.

The results obtained for Max $\theta_{4 / \text { rev }}$ and Max $\theta_{3 / \text { rev }}$ cases are very close to each other. This is specific to this problem and it can be attributed to the bounds used for constraints and design variables in the optimization problem definition. The only noticeable difference between the Max $\theta_{4 / \text { rev }}$ case and Max $\theta_{3 / \text { rev }}$ case is in the thickness of active plies.

For the Max $\theta_{5 / \text { rev }}$ case, the second ballast mass is also used to tune the first torsion frequency of the blade. The total ballast mass used in the Max $\theta_{5 / \text { rev }}$ case is higher than that used in the cases discussed above. Thus, for the Max $\theta_{5 / \text { rev }}$ case, the optimizer takes advantage of both, the higher active twisting moment and dynamic tuning, to obtain large amplitude of oscillation at the blade tip. In the Max $\theta_{5 / \text { rev }}$ case also, small changes are observed in the ply angle for active ply. But the most noticeable change occurs in the ply angle for nose ply, which changes to 62.2 degrees. Similar to the Max $\theta_{3 / \text { rev }}$ case, the changes in ply angle result in lower active twisting and also lower torsional stiffness and first torsion frequency. The result obtained for Max $\theta_{345 / \text { rev }}$ case is the same as that obtained for Max $\theta_{5 / \text { rev }}$ case. 
Table 18: Results for optimization with Continuous Design Variables

\begin{tabular}{|c|c|c|c|c|c|c|}
\hline Cases & $\operatorname{Max} \theta_{\text {stat }}$ & $\operatorname{Max} \theta_{3 / \text { rev }}$ & $\operatorname{Max} \theta_{4 / \mathrm{rev}}$ & $\operatorname{Max} \theta_{5 / \mathrm{rev}}$ & $\operatorname{Max} \theta_{345 / \text { rev }}$ & Baseline 2 \\
\hline \multicolumn{7}{|c|}{ Objective Function } \\
\hline$\theta_{\text {stat }}(\mathrm{deg} / \mathrm{m})$ & 2.49 & 2.22 & 2.24 & 2.4 & 2.4 & 1.67 \\
\hline$\theta_{\text {dyn,3rev }}(\operatorname{deg})$ & 3.67 & 4.91 & 4.66 & 3.9 & 3.9 & 2.4 \\
\hline$\theta_{\text {dyn,4rev }}(\mathrm{deg})$ & 4.48 & 5.89 & 5.94 & 5.29 & 5.29 & 2.54 \\
\hline$\theta_{\text {dyn,5rev }}(\mathrm{deg})$ & 6.81 & 3.53 & 4.31 & 8.02 & 8.02 & 2.38 \\
\hline$\theta_{\text {dyn }, 345 \mathrm{rev}}$ & 0.784 & 0.811 & 0.828 & 0.895 & 0.895 & 0.408 \\
\hline \multicolumn{7}{|c|}{ Constraints } \\
\hline $1^{\text {st }}$ Tor Freq(/rev) & 6.01 & 4.51 & 4.69 & 5.32 & 5.32 & 5.48 \\
\hline $\mathrm{M}_{11}(\mathrm{~kg} / \mathrm{m})$ & 0.72 & 0.719 & 0.719 & 0.72 & 0.72 & 0.642 \\
\hline $\mathrm{SC}(\% \mathrm{c})$ & 24.8 & 17.29 & 17.14 & 22.16 & 22.16 & 19.01 \\
\hline $\mathrm{CG}(\% \mathrm{c})$ & 27.75 & 27.79 & 27.75 & 27.99 & 27.99 & 21.87 \\
\hline \multicolumn{7}{|c|}{ Design Variables } \\
\hline Spar End (c) & 0.85 & 0.85 & 0.85 & 0.85 & 0.85 & 0.443 \\
\hline Spar Web (c) & 0.85 & 0.309 & 0.319 & 0.85 & 0.85 & 0.443 \\
\hline $\mathrm{m}_{1}(\mathrm{~kg} / \mathrm{m})$ & 0.299 & 0.309 & 0.307 & 0.33 & 0.33 & 0.23 \\
\hline $\mathrm{m}_{2}(\mathrm{~kg} / \mathrm{m})$ & 0 & 0 & 0 & 0.036 & 0.036 & 0.22 \\
\hline \multicolumn{7}{|c|}{ Normalized Ply Thicknesses } \\
\hline Ply 2a (S-Glass) & 4.88 & 1 & 1.54 & 4.91 & 4.91 & 1 \\
\hline Ply 2 (AFC) & 1.23 & 1.37 & 1 & 1 & 1 & 1 \\
\hline Ply 4 (AFC) & 1.24 & 1 & 1.36 & 1 & 1 & 1 \\
\hline Ply 6 (E-Glass) & 1.2 & 10 & 10 & 1 & 1 & 1 \\
\hline \multicolumn{7}{|c|}{ Ply Angles } \\
\hline Ply 1 (E-Glass) & 0 & 0 & 0 & 0 & 0 & 0 \\
\hline Ply 2a (S-Glass) & 0 & 1.9 & 0 & 62.2 & 62.2 & 0 \\
\hline Ply 2 (AFC) & 45 & 43.5 & 45 & -42 & -42 & 45 \\
\hline Ply 4 (AFC) & -45 & -54.9 & -45 & 47.1 & 47.1 & -45 \\
\hline Ply 6 (E-Glass) & 0 & 0 & 0 & 0 & 0 & 0 \\
\hline \multicolumn{7}{|c|}{ Other Parameters } \\
\hline $\mathrm{S}_{44}\left(\mathrm{Nm}^{2}\right)$ & 66.2 & 34.8 & 37.9 & 57.4 & 57.4 & 25.1 \\
\hline Act Mom (Nm) & 2.87 & 1.48 & 1.61 & 2.42 & 2.42 & 0.76 \\
\hline $2^{\text {nd }}$ Flap Freq $(/ \mathrm{rev})$ & 2.79 & 2.78 & 2.79 & 2.76 & 2.76 & 2.72 \\
\hline $3^{\text {rd }}$ Flap Freq $(/ \mathrm{rev})$ & 5.51 & 5.47 & 5.51 & 9.31 & 9.31 & 5.07 \\
\hline $\operatorname{Max} \varepsilon_{11}(\mu \varepsilon)$ & 2478 & 3906 & 3547 & 4508 & 4508 & 3935 \\
\hline $\operatorname{Max} \varepsilon_{12}(\mu \varepsilon)$ & 4347 & 5263 & 4968 & 6201 & 6201 & 5591 \\
\hline
\end{tabular}

In the optimization studies presented in this section, the cross-sectional strains are not included as part of the constraints. The results obtained here show that the maximum value of $\varepsilon_{11}$ and $\varepsilon_{12}$ in the cross section for all the optimized cases is approximately equal to or less than that obtained for the baseline case. Thus, the blade designs obtained from these optimization studies have sufficient strength to withstand the large centrifugal loads.

\section{Optimization with Mixed Design Variables}

For the results presented in this section, the normalized ply thicknesses and angles are treated as discrete design variables. In the previous section, it was shown that the optimization with mixed design variables can be performed in three different ways. The mixed solutions, "Mixed Solution 1" and "Mixed Solution 2", are obtained using the genetic mixed-variable optimization while the "Mixed Solution 3" is obtained using a gradient based optimizer only. The results obtained earlier showed that the final results obtained for the objective function with different mixed 
design variables optimization techniques are close to each other. Also, it was observed that obtaining the "Mixed Solution 3" required significant computational time since the optimization is performed in a recursive manner. Hence, in this section, the mixed-variable optimization is performed to obtain "Mixed Solution 1" and "Mixed Solution 2" only. The final results presented here in Table 19 show only the best result obtained with mixed design variables. As observed in the results with continuous optimization, for some of the objective functions considered, the ply angles for the optimized cases are the same as those for the baseline case.

Table 19: Results Obtained for Optimization with Mixed Design Variables

\begin{tabular}{|c|c|c|c|c|c|c|}
\hline Cases & $\operatorname{Max} \theta_{\text {stat }}$ & $\operatorname{Max} \theta_{3 / \mathrm{rev}}$ & $\operatorname{Max} \theta_{4 / \text { rev }}$ & $\operatorname{Max} \theta_{5 / \mathrm{rev}}$ & $\operatorname{Max} \theta_{345 / \mathrm{rev}}$ & Baseline 2 \\
\hline \multicolumn{7}{|c|}{ Objective Function } \\
\hline$\theta_{\text {stat }}(\operatorname{deg} / \mathrm{m})$ & 2.41 & -2.22 & -2.21 & 2.39 & -2.39 & 1.67 \\
\hline$\theta_{\text {dyn,3rev }}(\operatorname{deg})$ & 3.36 & 4.6 & 4.34 & 3.81 & 3.88 & 2.4 \\
\hline$\theta_{\text {dyn,4rev }}(\mathrm{deg})$ & 4.3 & 5.28 & 5.41 & 5.01 & 5.31 & 2.54 \\
\hline$\theta_{\text {dyn, } 5 \text { rev }}(\mathrm{deg})$ & 5.73 & 3.86 & 4.81 & 7.87 & 7.62 & 2.38 \\
\hline$\theta_{\text {dyn,345rev }}$ & 0.708 & 0.769 & 0.798 & 0.867 & 0.878 & 0.408 \\
\hline \multicolumn{7}{|c|}{ Constraints } \\
\hline $1^{\text {st }}$ Tor Freq (/rev) & 5.71 & 4.71 & 4.93 & 5.48 & 5.28 & 5.48 \\
\hline $\mathrm{M}_{11}(\mathrm{~kg} / \mathrm{m})$ & 0.694 & 0.688 & 0.697 & 0.697 & 0.72 & 0.642 \\
\hline $\mathrm{SC}(\% \mathrm{c})$ & 23.81 & 17.05 & 17.19 & 21.51 & 24.77 & 19.01 \\
\hline $\mathrm{CG}(\% \mathrm{c})$ & 20.33 & 27.92 & 27.79 & 27.95 & 28 & 21.87 \\
\hline \multicolumn{7}{|c|}{ Design Variables } \\
\hline Spar End (c) & 0.85 & 0.849 & 0.85 & 0.839 & 0.846 & 0.443 \\
\hline Spar Web (c) & 0.85 & 0.303 & 0.318 & 0.839 & 0.843 & 0.443 \\
\hline $\mathrm{m}_{1}(\mathrm{~kg} / \mathrm{m})$ & 0.332 & 0.271 & 0.273 & 0.313 & 0.334 & 0.23 \\
\hline $\mathrm{m}_{2}(\mathrm{~kg} / \mathrm{m})$ & 0.009 & 0.063 & 0.06 & 0.034 & 0.038 & 0.22 \\
\hline \multicolumn{7}{|c|}{ Normalized Ply Thicknesses } \\
\hline Ply 2a (S-Glass) & 5 & 1 & 2 & 5 & 4 & 1 \\
\hline Ply 2 (AFC) & 1 & 1 & 1 & 1 & 1 & 1 \\
\hline Ply 4 (AFC) & 1 & 1 & 1 & 1 & 1 & 1 \\
\hline Ply 6 (E-Glass) & 1 & 9 & 10 & 1 & 1 & 1 \\
\hline \multicolumn{7}{|c|}{ Ply Angles } \\
\hline Ply 1 (E-Glass) & 0 & 0 & 0 & 87 & 0 & 0 \\
\hline Ply 2a (S-Glass) & 0 & 0 & 0 & -28 & 0 & 0 \\
\hline Ply 2 (AFC) & 45 & 45 & 45 & -45 & 45 & 45 \\
\hline Ply 4 (AFC) & -45 & -45 & -45 & 45 & -45 & -45 \\
\hline Ply 6 (E-Glass) & 0 & 0 & 0 & 1 & 0 & 0 \\
\hline \multicolumn{7}{|c|}{ Other Parameters } \\
\hline $\mathrm{S}_{44}\left(\mathrm{Nm}^{2}\right)$ & 56.5 & 32.9 & 37 & 58.1 & 55.8 & 25.1 \\
\hline Act Mom (Nm) & 2.38 & 1.37 & 1.54 & 2.44 & 2.33 & 0.76 \\
\hline $2^{\text {nd }}$ Flap Freq (/rev) & 2.77 & 2.77 & 2.78 & 2.76 & 2.76 & 2.72 \\
\hline $3^{\text {rd }}$ Flap Freq (/rev) & 5.4 & 5.42 & 5.44 & 5.35 & 5.36 & 5.07 \\
\hline $\operatorname{Max} \varepsilon_{11}(\mu \varepsilon)$ & 2489 & 3994 & 3364 & 1340 & 2896 & 3935 \\
\hline $\operatorname{Max} \varepsilon_{12}(\mu \varepsilon)$ & 4220 & 5600 & 4748 & 6765 & 4711 & 5591 \\
\hline
\end{tabular}

The shape of the cross section for the optimized cases is shown in Figure 7. In these section, the leading edge ballast mass is presented by a red circle while the ballast mass used near the vertical spar web is represented by a blue circle. 

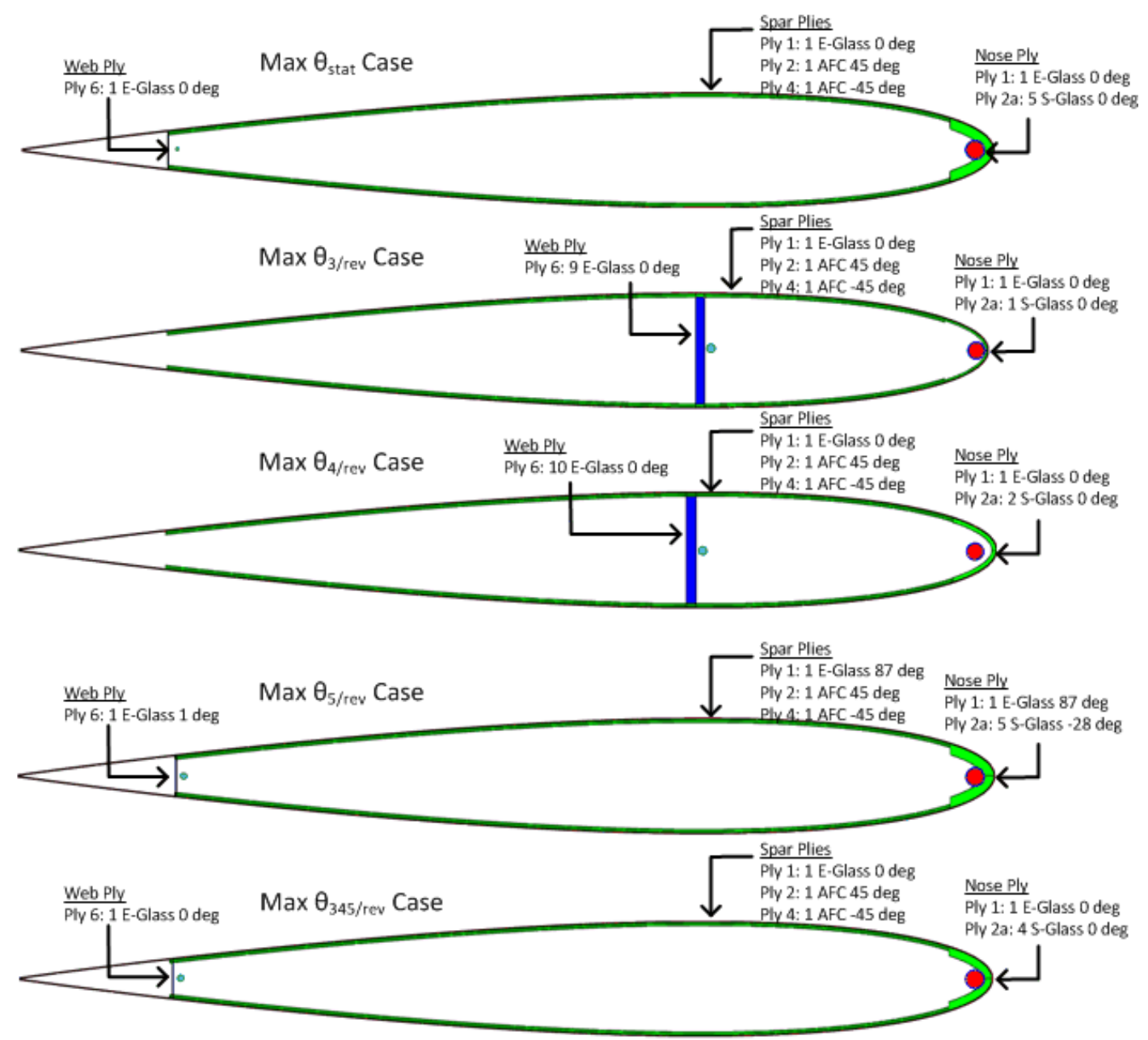

Figure 7: Cross Section for the Optimized Cases obtained with Mixed Design Variables

\section{Post Processing of Optimization Results}

The final results obtained at the end of optimization process with mixed design variables, as shown in Table 19, are analyzed further in order to check their validity. Here three different kinds of analyses are performed. In the first check, the variation of vibratory loads in forward flight condition is analyzed when no twist actuation is applied in order to make sure that the optimized designs do not lead to higher baseline vibration (vibration level in the absence of twist actuation). In the second analysis, variation of the amplitude of dynamic twist with advance ratio is determined for different actuation frequencies. And finally, circle plots are generated for each of the optimized cases in forward flight condition at different actuation frequencies in order make sure that the optimized results do provide higher authority for vibration reduction at the hub.

\section{Effect on Baseline Vibration}

In this case, the aeroelastic analysis for each of the optimized cases and baseline case is performed at $\mu=0.24$ using the "Trim Analysis". When the trim condition is reached, the amplitude of 4/rev vibratory load at the hub in fixed system is recorded. The percentage difference in the vibratory loads for $F_{z}, M_{x}$ and $M_{y}$ (components of hub loads in the fixed frame) with respect to the baseline case is shown in Figure 8. 

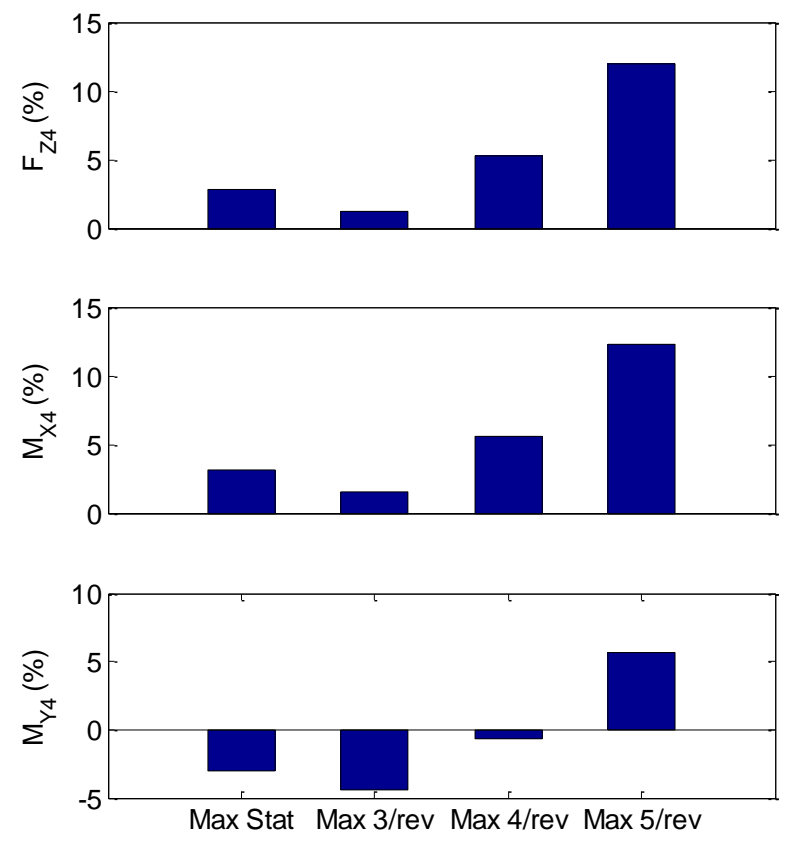

Figure 8: Percentage Increase in Vibratory Loads

The results obtained show that the increase in baseline vibration is less than $13 \%$ for all the optimized cases. Among all the cases, the "Max $\theta_{5 / \text { rev }}$ " case shows highest baseline vibration.

\section{Effect of Advance Ratio}

In this section, aeroelastic studies with "Trim Analysis" were performed for each of the optimized cases at different forward flight speeds. This study was performed to verify the original assumption that there is no significant change in the amplitude of tip twist with forward flight speed. The results obtained for actuation frequencies of 3, 4 and 5/rev are shown in Figure 9, Figure 10 and Figure 11, respectively. The results obtained show that the variation in the amplitude of dynamic tip twist with advance ratio is small. Since the results presented here include "Trim Analysis", they do not match exactly the results shown in Table 19 where "Periodic Analysis" is used. For each of the actuation frequency, the corresponding case provides maximum dynamic twist at all the advance ratios considered.

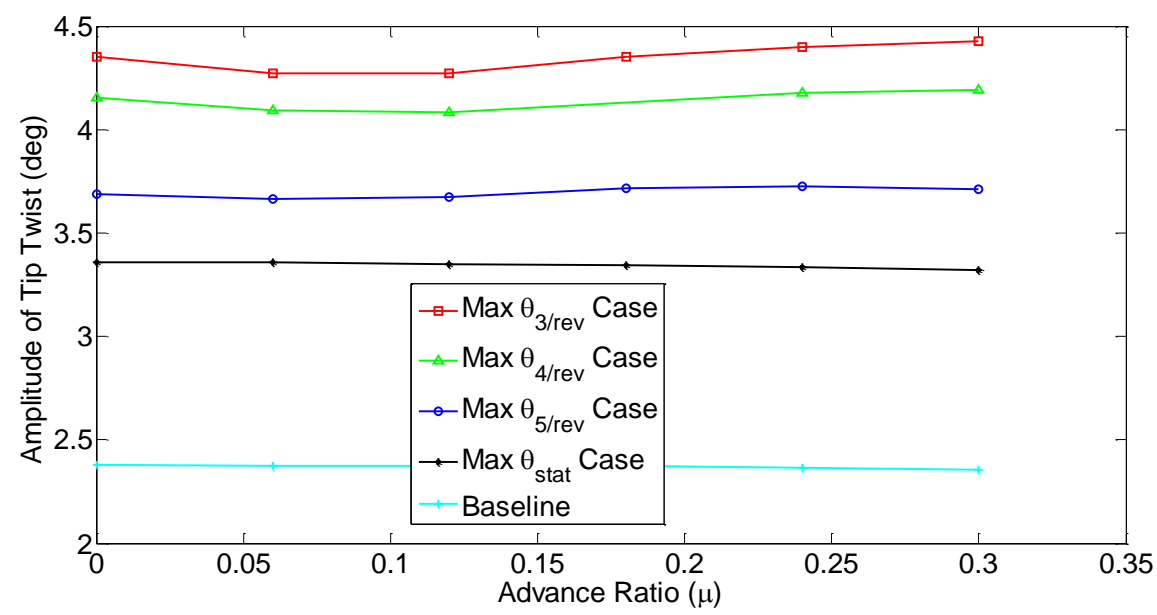

Figure 9: Effect of advance ratio at 3/rev actuation frequency 


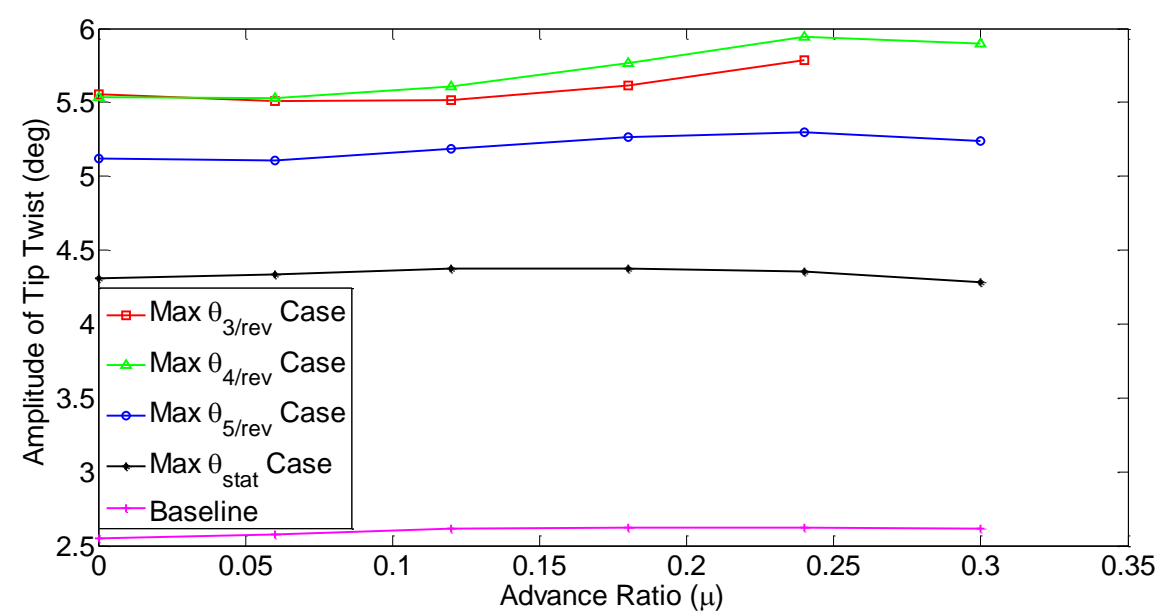

Figure 10: Effect of Advance Ratio at 4/rev Actuation Frequency

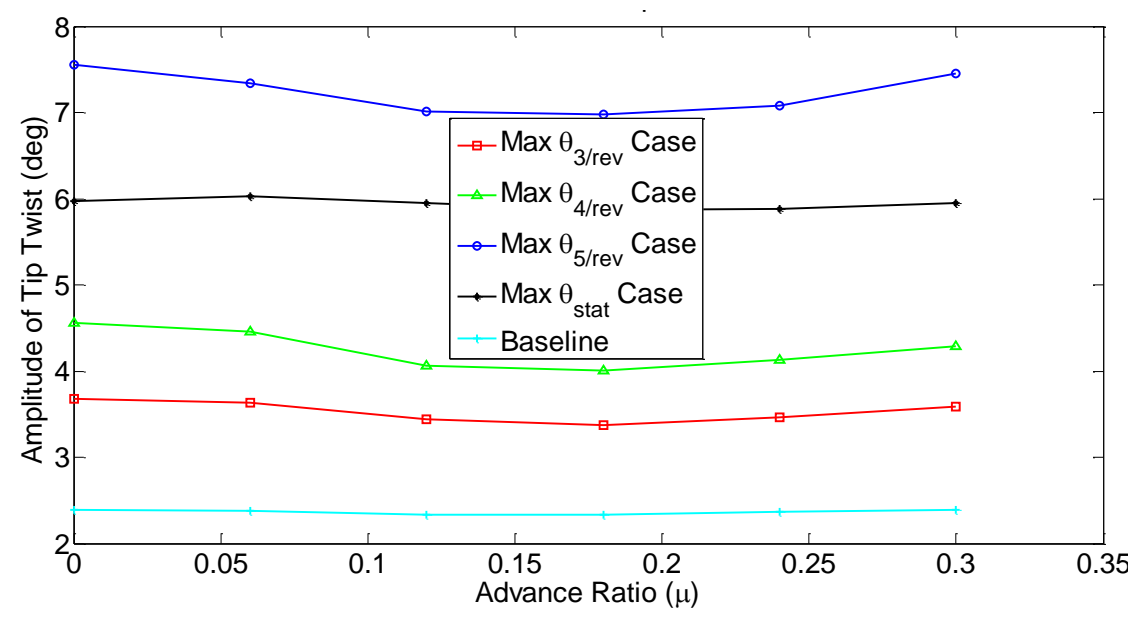

Figure 11: Effect of Advance Ratio at 5/rev Actuation Frequency

\section{Circle Plot for Optimized Cases}

In order to generate circle plot for each of the optimized cases and the baseline case, the twist actuation is provided at a fixed frequency and the phase of actuation is varied from 0 to 360 degree in the intervals of 30 degree. Once the response for each of the hub loads in the fixed system is obtained, FFT is used to determine the sine and cosine component of the response corresponding to 4/rev frequency. The circle plots generated for 3/rev, 4/rev and $5 /$ rev actuation frequencies for vertical component of the force at the hub $\left(F_{z}\right)$ are shown in Figure 12, Figure 13 and Figure 14, respectively.

Since the optimum result obtained for the "Max $\theta_{3 / \text { rev }}$ " and "Max $\theta_{4 \text { rev }}$ " cases are close to each other, the circle plots corresponding to these cases for 3/rev and 4/rev actuation frequencies are close to each other. As shown in Figure 12 and Figure 13, the circle plot corresponding to "Max $\theta_{5 / \text { rev }}$ " case has larger size than that corresponding to "Max $\theta_{\text {stat }}$ " case. Thus, each of the dynamically optimized cases performs better than the statically optimized case for $3 /$ rev and $4 /$ rev actuation frequency. 


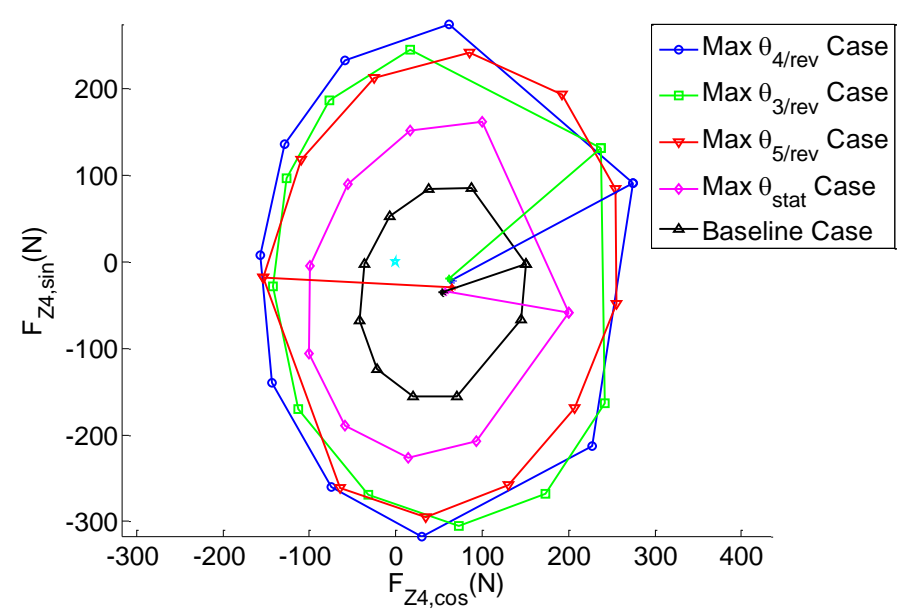

Figure 12: Circle Plot for 3/rev Actuation Frequency

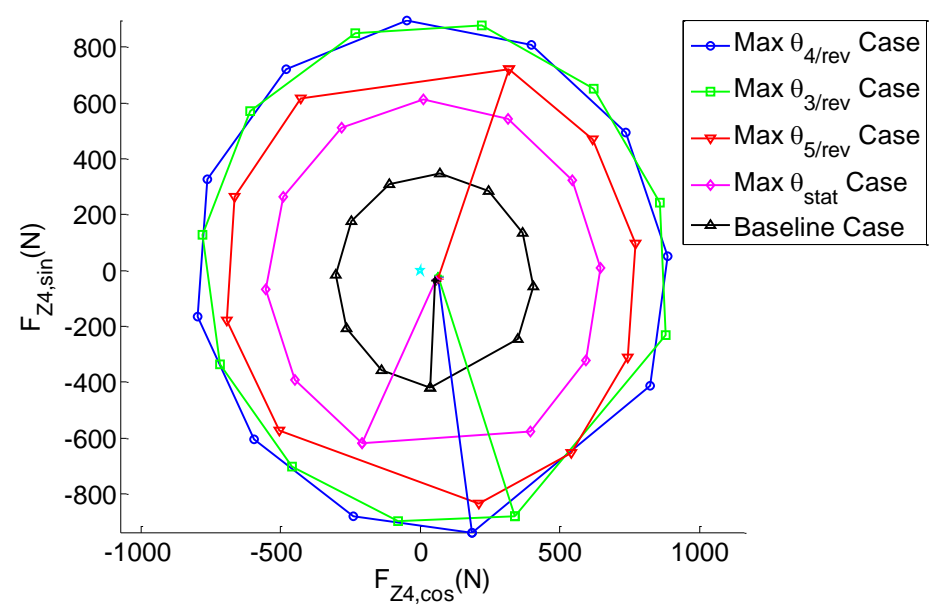

Figure 13: Circle Plot for 4/rev Actuation Frequency

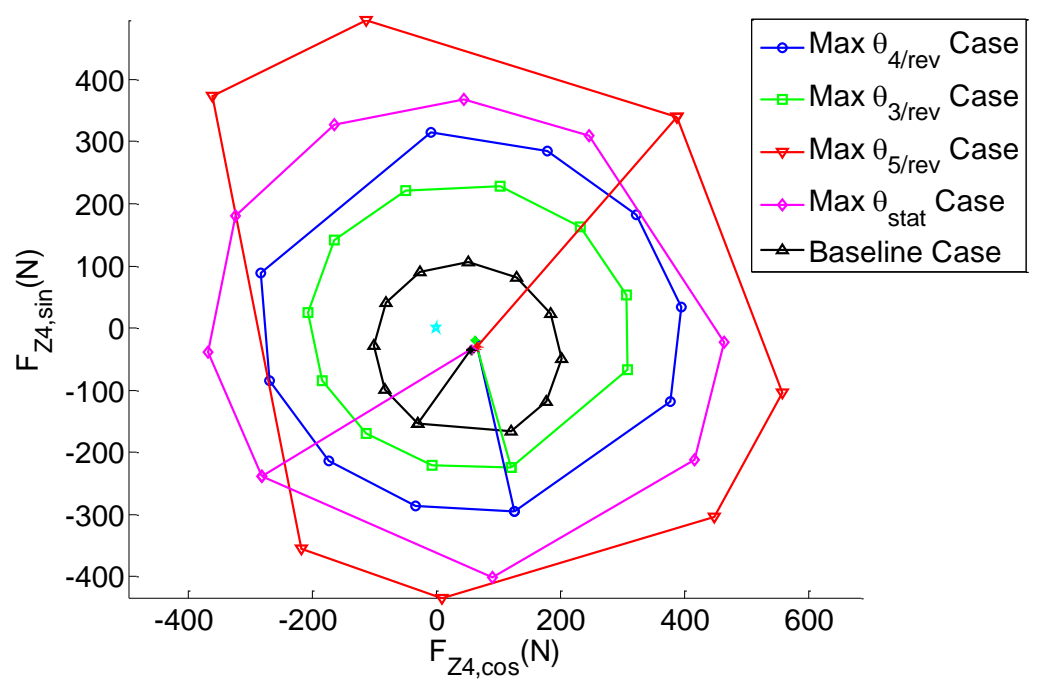

Figure 14: Circle Plot for 5/rev Actuation Frequency

In case of circle plot generated at $5 / \mathrm{rev}$ actuation frequency, the "Max $\theta_{5 / \text { rev }}$ " case is the most effective for vibration reduction as shown in Figure 14. Since, the optimum design for "Max $\theta_{\text {stat }}$ " case is close to that for "Max 
$\theta_{5 / \text { rev }}$ " case, the "Max $\theta_{\text {stat }}$ " case outperforms the "Max $\theta_{3 / \text { rev }}$ " and "Max $\theta_{4 / \text { rev }}$ " cases for vibration reduction at $5 /$ rev actuation frequency.

The results presented in this section highlight the original assumption that authority of an active twist rotor to reduce vibratory loads at the hub can be increased by maximizing the amplitude of dynamic twist obtained from twist actuation.

\section{Concluding Remarks}

The use of prepreg material for manufacturing composite aerospace structures leads to discrete design variables in the design and optimization studies. In order to obtain a realistic and manufacturable design at the end of optimization, the ply thicknesses and ply angles should be treated as discrete design variables. This paper presented the architecture of a design framework which can be used to perform optimization studies with mixed design variables for designing a composite active twist rotor blade. In the proposed framework, the optimum solution with mixed design variables is obtained using three different methods, in addition to the optimum design when all the variables are treated as continuous. This facilitates the designer to estimate the loss due to "discretization" and make necessary changes to improve the design.

The mixed design variable optimization framework was successfully used to design the cross section of a composite rotor blade with embedded active material. In the first case, ply thicknesses were considered as discrete design variables, in addition to the continuous design variables like the chordwise location of vertical spar web, ballast masses and chordwise location where the active plies end. Here, the minimum allowable normalized thickness of prepreg plies was fixed at " 0.1 " instead of " 0 " to prevent the finite element mesh generator from crashing. The results obtained from these studies showed that some of the plies had normalized ply thickness as " 0.1 " in the optimum results, indicating that these plies should be removed from the analysis. In the next step, these passive plies were removed from the cross section (except the outermost ply whose normalized thickness was fixed to "1") and the minimum allowable normalized thickness was modified to "1". In this case, the ply angles for remaining plies were also considered as design variables.

The final results obtained showed that:

1) The optimization studies for maximizing the amplitude of dynamic twist can be performed in hover condition (instead of multiple advance ratios) using periodic analysis (instead of full trim analysis) within a design cycle in order to reduce the computation time.

2) The difference between the results obtained from continuous and mixed-variable optimization depends on the objective function being considered.

3) The mixed design variable results obtained using three methods are close to each other. And it is sufficient to obtain only the "Mixed Solution 1" and "Mixed Solution 2" to predict the optimum solution with mixed design variables since the "Mixed Solution 3 " is very time consuming.

4) While maximizing the static and dynamic twist, the optimum design obtained always led to a stiffer cross section and thus most of the optimum designs had lower cross sectional strains (except for 3/rev actuation frequency case).

5) A thick prepreg layer is required near the leading edge (Ply 2a) to obtain higher active twisting moment, but it may increase the torsional stiffness which may cause the dynamic twist performance to deteriorate.

6) For a fixed amount of active material available, the results obtained showed that increasing the chordwise coverage of active plies leads to higher static and dynamic twist as compared to increasing the thickness of active plies. Also, a boxed-shaped spar design, in which the chordwise location where the spar plies end and the chordwise location of vertical spar web are close to each other, is suitable for maximizing the dynamic twist amplitude.

7) There is a significant difference in the optimum design obtained for different actuation frequencies.

8) For the results obtained for this particular case, the optimum design obtained by maximizing amplitude of dynamic twist at 3,4 and 5/rev actuation frequencies tends to be closer to result obtained for maximizing amplitude for $5 / \mathrm{rev}$ actuation frequency. This can be attributed to the higher cross-sectional stiffness in Max $\theta_{5 / \text { rev }}$ case which in turn results in higher active twisting moment. 


\section{Acknowledgments}

This work was sponsored by the US Army Research, Development and Engineering Command (AMRDEC), Aviation Applied Technology Directorate (AATD) through SBIR Phase II contract \# W911W6-10-C-0030. Authors would like to thank Dr. Peter Röhl (Advatech Pacific, Inc) for providing IXGEN and for implementing the aeroelastic analysis environment in ModelCenter.

\section{References}

[1] Kessler, C., "Active Rotor Control for Helicopters: Motivation and Survey on Higher Harmonic Control," CEAS Aeronautical Journal, Vol. 1, No. 1, 2011, pp. 3-22.

[2] Kessler, C., "Active Rotor Control for Helicopters: Individual Blade Control and Swashplateless Rotor Designs," CEAS Aeronautical Journal, Vol. 1, No. 1-4, 2011, pp. $23-54$.

[3] Shin, S., Cesnik, C. E. S., Wilkie, W. K., and Wilbur, M. L., "Design and Manufacturing of a Model-scale Active Twist Rotor Prototype Blade," Journal of Intelligent Material Systems and Structures, Vol. 19, No. 12, 2008, pp. 1443-1456.

[4] Rodgers, J. P., Hagood, N. W., and Weems, D., "Design and Manufacture of an Integral Twist-Actuated Rotor Blade," 38th AIAA/ASME/ASCE/AHS/ASC Structures, Structural Dynamics, and Materials Conference, Kissimmee, FL, April 7-10, 1997.

[5] Riemenschneider, J., Keye, S., Wierach, P., and Rochettes, H.-M. d., "Overview of the Common DLR/ONERA Project "Active Twist Blade" (ATB)," 30th European Rotorcraft Forum, Marseilles, France, 14-16 September, 2004.

[6] Kumar, D., "Design and Analysis of Composite Rotor Blades for Active/Passive Vibration Reduction," PhD Dissertation, Department of Aerospace Engineering, University of Michigan, 2013.

[7] Thakkar, D., and Ganguli, R., "Active Twist Control of Smart Helicopter Rotor - A Survey," Journal of Aerospace Sciences and Technologies, Vol. 57, No. 4, 2005, pp. 1-20.

[8] Cesnik, C. E. S., Shin, S., Wilkie, W. K., Wilbur, M. L., and Mirick, P. H., "Modeling, Design and Testing of the NASA/ARMY/MIT Active Twist Rotor Prototype Blade," American Helicopter Society 55th Annual Forum Montreal, Canada, May 25-27, 1999.

[9] Cesnik, C. E. S., Mok, J., Parekh, A., and Shin, S., "Optimization Design Framework for Integrally Twisted Helicopter Blades," 45th AIAA/ASME/ASCE/ASC Structures, Structural Dynamics and Materials Conference, Palm Springs, California, 19-22 April, 2004.

[10] Cesnik, C. E. S., Mok, J., Morillo, J. A., and Parikh, A. S., "Design Optimization of Active Twist Rotor Blades," 30th European Rotorcraft Forum, Marseilles, France, 2005.

[11] Mok, J., "Design Optimization for Active Twist Rotor Blades," PhD Dissertation, Department of Aerospace Engineering, University of Michigan, Ann Arbor, Michigan, 2010.

[12] Palacios, R., and Cesnik, C. E. S., "Cross-Sectional Analysis of Nonhomogeneous Anisotropic Active Slender Structures," AIAA Journal, Vol. 43, No. 12, 2005, pp. 2624-2638.

[13] Bauchau, O., "DYMORE User's Manual," Georgia Institute of Technology, 2007.

[14] Thornburgh, R. P., Kreshock, A. R., and Wilbur, M. L., "Structural Optimization of Active-Twist Rotor Blades," American Helicopter Society, 67th Annual Forum, Virginia Beach, VA, 3-5 May, 2011.

[15] Masarati, P., Morandini, M., Riemenschneider, J., Wierach, P., Gluhih, S., and Barkanov, E., "Optimal design of an Active Twist 1:2.5 Scale Rotor Blade," European Rotorcraft Forum, Florence, Italy, September 13-15, 2005.

[16] Kovalos, A., Barakanov, E., and Gluhihs, S., "Active Twist Model Rotor Blades with D-Spar Design," Transport, Vol. XXII, No. 1, 2007, pp. 38-44.

[17] Barakanov, E., Gluhih, S., and Kovalev, A., "Optimal Design of the Active Twist for Helicopter Rotor Blades with C-Spar," Mechanics of Advanced Materials and Structures, Vol. 15, No. 3-4, 2008, pp. 325334.

[18] Sekula, M. K., Wilbur, M. L., and Yeager, W. T., "Aerodynamic Design Study of an Advanced Active Twist Rotor," American Helicopter Society 4th Decennial Specialist Conference on Aeromechanics San Francisco, California, January 21-23, 2004.

[19] Sekula, M. K., Wilbur, M. L., and Yeager, W. T., "A Parametric Study of the Structural design of an Advanced Active Twist Rotor," American Helicopter Society 61st Annual Forum, Grapevine, Texas, June $1-3,2005$. 
[20] Wilbur, M. L., and Sekula, M. K., "The Effect of Tip Geometry on Active-Twist Rotor Response," American Helicopter Society 61st Annual Forum, Grapevine, Texas, 1-3 June 2005.

[21] Kumar, D., Cesnik, C., Rohl, P. J., and Sutton, M., "Optimization Framework for the Dynamic Analysis and Design of Active Twist Rotors," 68th American Helicopter Society International Annual Forum, Fort Worth, TX, 1-3 May, 2012.

[22] Ghiasi, H., Pasini, D., and Lessard, L., "Optimum Stacking Sequence Design of Composite Materials Part I: Constant Stiffness Design,” Composite Structures, Vol. 90, No. 1, 2009, pp. 1-11.

[23] Ghiasi, H., Fayazbakhsh, K., Pasini, D., and Lessard, L., "Optimum Stacking Sequence Design of Composite Materials Part II: Variable Stiffness Design,” Composite Structures, Vol. 93, No. 1, 2010, pp. 113.

[24] Gürdal, Z., IJsselmuiden, S., and Campen, J. v., "Composite Laminate Optimization with Discrete Variables," 2010.

[25] Kennedy, G. J., and Martins, J. J. R. A., "A Laminate Parametrization Technique for Discrete Ply Angle Problems with Manufacturing Constraints," Structural and Multidisciplinary Optimization, 2012.

[26] Kennedy, G. J., and Martins, J. J. R. A., "A Regularized Discrete Laminate Parametrization Technique with Applications to Wing-Box Design Optimization," 53rd AIAA/ASME/ASCE/AHS/ASC Structures, Structural Dynamics and Materials Conference, Honolulu, Hawaii, 23 - 26 April, 2012.

[27] Murugan, S., Ganguli, R., and Harursampath, D., "Surrogate based Design Optimization of Composite Airfoil Cross section for Helicopter Vibration Reduction," The Aeronautical Journal, Vol. 116, No. 1181, 2012, pp. 709-725.

[28] Glaz, B., Friedmann, P. P., Liu, L., Kumar, D., and Cesnik, C. E. S., "The AVINOR Aeroelastic Simulation Code and its Application to Reduced Vibration Composite Rotor Blade Design," 50th AIAA/ASME/ASCE/AHS/ASC Structures. Structural Dynamics, and Materials Conference, Palm Springs, California, 4-7 May, 2009.

[29] Guido, S. D., Geijselaers, H. J. M., and Boer, A. d., "Continuous-Discrete Variable Optimization on Composite using Kriging Surrogate Model," 16th International Conference on Composite Structures, Porto, Portugal, June 28-30, 2011.

[30] Kumar, D., Glaz, B., Mok, J., Friedmann, P. P., and Cesnik, C., "Determination of Optimum Camber Distribution in Rotating wings with Deformable Airfoils for Vibration Reduction and Performance Enhancement using Surrogate Modeling," Proceedings of European Rotorcraft Forum, Paris, France, 7-9 September, 2010.

[31] Deep, K., Singh, K. P., Kansal, M. L., and Mohan, C., "A Real coded Genetic Algorithm for solving Integer and Mixed-integer Optimization Problems," Applied Mathematics and Computation, Vol. 212, No. 2, 2009, pp. 505-518.

[32] Röhl, P. J., Dorman, P., Sutton, M., Cesnik, C. E. S., and Kumar, D., "IXGEN- A Modeling Tool for the Preliminary Design of Composite Rotor Blade," AHS Future Vertical Lift Design Conference San Francisco, 18-20 January 2012.

[33] Röhl, P. J., Dorman, P., Sutton, M., Kumar, D., and Cesnik, C., "A Multidisciplinary Design Environment for Composite Rotor Blades," 53rd AIAA/ASME/ASCE/AHS/ASC Structures, Structural Dynamics and Material Conference, Honolulu, Hawaii, 23 - 26 April 2012.

[34] Saberi, H., Khoshlahjeh, M., Ormiston, R., and Rutkowski, M., "Overview of RCAS and Application to Advanced Rotorcraft Problems," AHS 4th Decennial Specialist Conference on Aeromechanics, San Francisco, California, January 21-23, 2004.

[35] "Model Center 10.0",Phoenix Integration,Wayne, PA,2012

[36] Forester, A., Sobester, A., and Keane, A., Engineering design via Surrogate Modeling: A Practical Guide, AIAA, John Wiley and Sons, Ltd, 2008.

[37] Queipo, N. V., Haftka, R. T., Shy, W., Goel, T., Vaidyanathan, R., and Tucker, P. K., "Surrogate based Analysis and Optimization," Progress in Aerospace Sciences, Vol. 41, 2005, pp. 1-28.

[38] Sacks, J., Welch, W. J., Mitchell, T. J., and Wynn, H. P., "Design and Analysis of Computer Experiments," Statistical Science, Vol. 4, No. 4, 1989, pp. 409-435.

[39] Lophaven, S. N., Nielsen, H. B., and Sondergaard, J., "A Matlab Kriging Toolbox, version 2.0," Informatics and Mathematical Modeling, 2002.

[40] Jones, D. R., Schonlau, M., and Welch, W. J., "Efficient Global Optimization of Expensive Black Box Functions," Journal of Global Optimization, Vol. 13, 1998, pp. 455-492. 
[41] Glaz, B., Friedmann, P. P., and Liu, L., "Helicopter Vibration Reduction throughout the Entire Flight Envelope Using Surrogate-Based Optimization,” Journal of American Helicopter Society, Vol. 54, No. 1, 2009, pp. 12007-1-12007-15.

[42] Cesnik, C. E. S., Shin, S., and Wilbur, M. L., "Dynamic Response of Active Twist Rotor Blades," Smart Materials and Structures, Vol. 10, 2001, pp. 62-76.

[43] Shin, S., Cesnik, C. E. S., and Hall, S. R., "Closed Loop Control Test of the NASA/Army/MIT Active Twist Rotor for Vibration Reduction," Journal of American Helicopter Society, Vol. 50, No. 2, 2005, pp. 178-194.

[44] Li, L., Volovoi, V., and Hodges, D., "Cross-Sectional Design of Composite Rotor Blades," Journal of the American Helicopter Society, Vol. 53, No. 1, 2008, pp. 240-251. 